\title{
Insights into the Genetic Foundations of Human Communication
}

\author{
Sarah A. Graham • Pelagia Deriziotis • Simon E. Fisher
}

Received: 5 September 2014 / Accepted: 22 December 2014 /Published online: 18 January 2015

(C) Springer Science+Business Media New York 2015

\begin{abstract}
The human capacity to acquire sophisticated language is unmatched in the animal kingdom. Despite the discontinuity in communicative abilities between humans and other primates, language is built on ancient genetic foundations, which are being illuminated by comparative genomics. The genetic architecture of the language faculty is also being uncovered by research into neurodevelopmental disorders that disrupt the normally effortless process of language acquisition. In this article, we discuss the strategies that researchers are using to reveal genetic factors contributing to communicative abilities, and review progress in identifying the relevant genes and genetic variants. The first gene directly implicated in a speech and language disorder was FOXP2. Using this gene as a case study, we illustrate how evidence from genetics, molecular cell biology, animal models and human neuroimaging has converged to build a picture of the role of FOXP2 in neurodevelopment, providing a framework for future endeavors to bridge the gaps between genes, brains and behavior.
\end{abstract}

Keywords Communication · Speech and language · Neurodevelopmental disorder · Genetics · FOXP2

Sarah A. Graham and Pelagia Deriziotis contributed equally.

S. A. Graham • P. Deriziotis · S. E. Fisher

Language and Genetics Department, Max Planck Institute for

Psycholinguistics, Nijmegen 6525XD, The Netherlands

\section{S. E. Fisher $(\bowtie)$}

Donders Institute for Brain, Cognition and Behaviour, Radboud

University, Nijmegen 6525EN, The Netherlands

e-mail: simon.fisher@mpi.nl

\section{Introduction}

The acquisition of language is a formidable cognitive task, yet children typically achieve mastery of their native tongues without conscious effort, simply through engaging with the everyday conversation of those around them. In this review, we describe the progress made so far in elucidating the genetic underpinnings of this remarkable human ability, with consideration of how language is entwined with other cognitive systems in an evolutionary and developmental context. We aim to provide a broad perspective on genetic research into language and communication, and are therefore unable to offer a comprehensive discussion of research in every area, but instead highlight recent developments, important themes, and avenues for future investigation, and point interested readers to in-depth reviews of individual topics.

\section{Gateways into the Genetics of Language}

The Evolutionary Perspective

Genome sequences are now available for dozens of vertebrate species, including 10 or so primates and two species of extinct hominin, Neandertal and Denisovan, enabling evolutionary comparisons, and the detection of signals of positive selection in the human lineage (Gaya-Vidal and Alba 2014). The integration of genetic data with information from ethology, comparative neuroscience and archaeology is revitalizing thinking on the evolution of language (Fisher and Marcus 2006; Dediu and Levinson 2013; Rilling 2014). Looking ahead, an important complement to comparative genomics will be the use of comparative transcriptomics and proteomics to uncover evolutionary changes in the regulation of neural gene expression, which may have been more important than modifications of 
the genes themselves in the evolution of the human brain (Khan et al. 2013).

\section{Emergence of Language in the Human Lineage}

Though many of the facts of language evolution will remain obscure, it is very likely that the human capacity for language evolved from a genomic substrate present in the last common ancestor of humans and chimpanzees and bonobos, through the gradual accumulation of genetic changes over the intervening 6 million years (Fisher and Marcus 2006). Some cognitive precursors to language that are evident in chimpanzees and bonobos today are likely to have been present in this ancestor, including the intelligence for problem solving, the capacity for cultural innovation and learning, and a basic theory of mind that enables the attribution of mental states to others (Horner and de Waal 2009; Call and Tomasello 2008; Seyfarth and Cheney 2014).

Although chimpanzees and bonobos cannot remotely match the linguistic capabilities of a human child, careful observation and experiment has shown that they have greater communicative abilities than previously thought (Zuberbuhler 2014). These primates are very limited in their range of vocalizations and ability to control and learn vocalizations, but chimpanzees in the wild use a basic repertoire of gestures for intentional communication in order to achieve goals (Hobaiter and Byrne 2014; Roberts et al. 2014). Chimpanzees and bonobos in captivity are able to map meanings onto arbitrary symbols and use these for communication with humans and conspecifics, including communication about objects and events not in the here and now, pointing to a communicative capacity that is latent in the wild (Lyn et al. 2014; Zuberbuhler 2014). However, the number of vocabulary items they can learn is very small in comparison to a human child, and they have an extremely limited ability to combine these items to convey more complex meanings, so there are still some apparent discontinuities between humans and other primates with regard to communicative abilities. The reason why the ancestors of humans went on to evolve fully-fledged language, but the ancestors of chimpanzees and bonobos did not, may relate to prior genetic changes pertaining to sociality in the human lineage (Matsuzawa 2013). Among the Great Apes, humans are uniquely prosocial, which increases the benefit-to-cost ratio of communication for individual fitness. The genetic basis of sociality is therefore a key topic in language evolution.

It has been suggested that in an environment where selection favored the development of more sophisticated communication in ancient hominins, the benefits of the vocal channel of communication provided a selective pressure for anatomical and neurological adaptations to increase the degree of control over vocalization and the range of sounds that could be produced (Fitch 2010; Simonyan 2014). The genetic basis for these changes is not yet known. Anatomical adaptations evident in the fossil record, together with other evidence, suggest that the last common ancestor of modern humans and Neandertals already had at least some capacity for speech and language (Dediu and Levinson 2013). As a consequence, both genomic changes that have occurred since the humanNeandertal split, and changes that occurred earlier in the human lineage, may have contributed to language evolution.

Human language is notable for its grammatical complexity. It is unclear to what extent this complexity has arisen due to genetically grounded cognitive developments versus cultural processes not requiring any attendant genetic change (Kirby et al. 2014). The enormous diversity in the grammatical rule systems of the world's languages indicates that the finer details of these rule systems are not genetically encoded (Evans and Levinson 2009). However, there may be cognitive constraints that limit the possible characteristics of these rule systems. We cannot yet conclude whether or not genetic factors contribute to cognitive processes that underlie aspects of grammatical processing.

Subsequent to the evolution of the capacity for language in modern humans, genetic factors may also have played a role in how new languages have arisen and changed in different parts of the world over time. This is most strikingly illustrated in communities where high rates of genetic deafness have driven the emergence of new languages that are signed rather than spoken (Gialluisi et al. 2013). A more widespread scenario may be language change through the process of genetic biasing, in which small inter-population differences in language production, perception or processing abilities with a genetic basis, are amplified over generations, leading to a shift in some aspect of the language (Dediu 2011). For example, inter-population differences in the anatomy of the vocal tract could influence the phonemic inventories of different languages.

\section{Insights from Animal Communication}

Human language is undoubtedly unique in the natural world. But nonhuman species which have independently evolved certain relevant features in their communication systems may be useful models for gaining insights into the neurobiology and genetics of language. A key example is the use of songbirds, particularly the zebra finch, to study auditoryguided vocal learning. This behavior seems to be strikingly rare in animal communication and depends on a neurobiological infrastructure that allows mappings to be built between sounds that are heard, and the motor outputs which produce them. Similarly to children acquiring spoken language, juvenile zebra finches learn their vocalizations incrementally during a critical period by imitating an adult (Bolhuis et al. 2010). The neural circuitry underlying vocal learning appears to be partly shared by humans and songbirds, despite these species 
being separated by large evolutionary distances, pointing to a deep homology (Fisher and Scharff 2009; Scharff and Petri 2011). Furthermore, the zebra finch genome has been sequenced, and sophisticated genetic experiments are possible in this species, such as the identification of neural molecules regulated by vocal behavior (Hilliard et al. 2012), and the manipulation of the expression levels of genes of interest during the critical song-learning period (Haesler et al. 2007). Zebra finch vocalizations are made up of acoustic units known as 'syllables', which are arranged in different ways in a rulegoverned fashion, producing a wide variety of sequences. Birdsong thus shows similarities to human language that go beyond vocal learning (Berwick et al. 2011). However, there is no evidence yet that songbirds attach meaning to syllables, or the way in which they are arranged, which limits the utility of birdsong as a model for human language.

We might shed further light on the neurobiological foundations of language by studying nonhuman mammals. Unfortunately, the rodent species which are the mainstay of molecular genetic research exhibit very limited vocal learning abilities, although they can still be used to study basic processes such as auditory-motor association learning (Kurt et al. 2012; French and Fisher 2014). Certain language-relevant behaviors have been investigated in species such as primates, dolphins, elephants, seals and dogs, including the learning of vocalizations and of vocal labels, and the use of turn taking in interaction (Fedurek and Slocombe 2011; Reichmuth and Casey 2014; Griebel and Oller 2012; Takahashi et al. 2013; Janik 2014; Stoeger and Manger 2014). Perhaps the most promising mammalian models with regard to vocal learning are bats, which have sophisticated vocal production and acoustic signal interpretation skills, and have been shown to learn and adapt their vocalizations for purposes such as organization of group foraging (Knornschild 2014). Initial studies have already demonstrated the feasibility of genetic manipulation in a bat species (Chen et al. 2013).

\section{The Developmental Perspective}

Native language proficiency is characterized by a vocabulary of thousands of words, complex syntax, the ability to differentiate fine shades of meaning, and an appreciation of nonliteral meanings and the social conventions of interaction. Proficiency for everyday communication is attained at 45 years of age, but the sophistication of language use continues to develop into adolescence. Thus, while first language acquisition does not depend on conscious effort or formal learning, it does require years of immersion in a community of competent speakers who provide linguistic input for the developing brain. Children are particularly sensitive to this kind of information from early infancy, perhaps even before birth, and automatically seek patterns in the input they receive. Even before they can understand language, infants show a strong predisposition to communicate via non-verbal means such as eye gaze, facial expression and gestures, using turn taking as a framework for interaction. To begin decoding the meanings of the utterances they hear, children draw on a host of different information sources, including linguistic and situational context, prosody, non-verbal cues from speakers, experience of past language use, knowledge of the world around, and inferences about the speaker's intentions and motivations. Language acquisition thus draws on a range of cognitive skills, which are likely to be influenced by a large network of genes. At the neurobiological level, acquiring language proficiency means developing the neural infrastructure for rapid, automatic interconversion of acoustic streams, meanings and motor outputs. Reading and writing, although they are human inventions, draw heavily on the same cognitive infrastructure as does spoken language, and bring in additional aspects of visual and motor processing. The modern synthesis of language neurobiology encompasses a greater range of brain regions than the classical view centered on Broca's and Wernicke's areas, involving highly distributed circuits in which different groups of neurons are active during different stages of processing (Hagoort 2014). Therefore, investigations of genetic influences on brain structure and function, including longitudinal studies, will be essential for understanding how genes may contribute to the neural architecture supporting language.

\section{Developmental Communication Disorders}

Given the complexity of the task, it may not be surprising that some children struggle, even if only temporarily, with some aspect of spoken or written language acquisition. For at least one child in 20, these difficulties are persistent and severe enough to interfere with their educational and social development (Law et al. 2000; Scerri and Schulte-Korne 2010). In a subset of cases, impairment is due to a medical condition which directly limits the ability to perceive or produce speech, such as deafness or a cleft palate. In other children, speech and language problems occur in the context of a broader range of cognitive deficits, which may result from brain trauma or be part of a neurodevelopmental disorder such as intellectual disability (ID) or autism spectrum disorder (ASD). Still, there remains a substantial number of children whose speech or language problems occur in the absence of any obvious explanatory factors. There is considerable evidence of a substantial genetic component to these unexplained speech and language impairments (Newbury and Monaco 2010; CarrionCastillo et al. 2013). Studies of such disorders not only have clinical and educational relevance, but can also help answer fundamental questions about the genetic architecture underpinning human speech and language. In the following sections we discuss a range of neurodevelopmental disorders in which speech- or language-related deficits are a core feature 
Table 1 Developmental communication disorders

Speech sound disorder Includes phonological disorder, in which (SSD) children experience problems learning to conceptualize sounds, and articulation disorder, in which children have difficulty learning to physically produce sounds, both resulting in substitutions and omissions of speech sounds. Common during language acquisition, affecting approximately $16 \%$ of 3 year old children, persisting in $4 \%$ of children at 6 years of age (Shriberg et al. 1999). The DSM-IV category of phonological disorder has been renamed to SSD in DSM-V.

Dysarthria

Childhood apraxia of speech (CAS)

Stuttering

Dyslexia

Specific language impairment (SLI)
Impaired control of speech musculature, resulting from neurological lesions or neurodevelopmental problems. Affected individuals experience disturbances in breathing control, laryngeal function and articulation resulting in slurred or slow speech. Often observed in other disorders, including CAS and EAS.

Problems with coordinating and sequencing the orofacial movements required for fluent speech, resulting in inconsistent speech errors, which increase with complexity of utterance. Sometimes described as a speech sound disorder. Also known as developmental verbal dyspraxia (DVD).

Disorder affecting the fluency of speech, characterized by involuntary repetitions or prolongations of syllables or words, or by pauses in speech, known as blocks. Onset is typically at ages $2-5$, affecting $5 \%$ of children. Persistent stuttering is present in $1 \%$ of the population (Kang and Drayna 2011). The DSM-IV category for stuttering has been renamed childhood onset fluency disorder in DSM-V.

Difficulties in the mastery of reading and/or spelling that cannot be explained by inadequate opportunities to learn, visual impairment, brain damage or other neurodevelopmental disorders, such as in terms of severity and sometimes cooccur with impairments in other cognitive domains. Prevalence is at least $5 \%$ in school age children (Scerri and SchulteKorne 2010). Also known as reading disability; referred to in DSM-V as specific learning disability with impairment in reading.

Unexplained delayed or disordered acquisition and/or use of spoken language (expressive and sometimes also receptive) that interferes with daily life or school work and is not explained by inadequate opportunities to learn, hearing loss, brain damage or other neurodevelopmental disorders, such as intellectual disability. intellectual disability. Deficits are variable
Table 1 (continued)

Deficits are variable in terms of severity and sometimes co-occur with impairments in other cognitive domains. Prevalence 5-8 \% in pre-school (Law et al. 2000; Tomblin et al. 1997). Sometimes persists into school-age and beyond. DSM-IV included the categories 'expressive language disorder' and 'mixed receptive-expressive language disorder', but in DSM-V these have been collapsed into 'language disorder'.
Social (pragmatic) communication disorder

Autism spectrum disorder (ASD)

Intellectual disability

(ID)
Difficulties with the use of language in a social context. Similar to language deficits found in autism, but without restricted and repetitive behaviors (Bishop et al. 2000). Also known as pragmatic language impairment.

Variable degrees of impairment in social interaction and communication, together with stereotyped, repetitive or restricted behaviours and interests, which emerge during childhood. IQ is variable, but often well below average. Language delay is often present and there are always deficits in using language in a social context. Two developmental patterns are observed: appearance of signs in infancy, or normal development up to 2-3 years followed by regression, particularly of language. Prevalence of $1 \%$. Four times more common in males than in females. Autistic features are observed in various known genetic syndromes, such as Rett syndrome and Fragile X syndrome. DSM$\mathrm{V}$ category autism spectrum disorder includes DSM-IV categories of autism, Asperger syndrome, pervasive developmental disorder not otherwise specified, childhood disintegrative disorder.

Umbrella term used to group a large and heterogeneous collection of disorders characterized by deficits in cognitive functions. Diagnosis requires an IQ $<70$, together with significant impairment in behaviours such as communication, selfcare, and social skills, which is evident before the age of 18. May be classified as mild (IQ 50-69), moderate (IQ 35-49) and severe or profound (IQ<35). Borderline intellectual disability refers to individuals with IQ 70-80. Delays in language development are common. ID is a feature of many genetic disorders. ID is syndromic if it occurs alongside other clinical features, such as physical abnormalities, or non-syndromic if it occurs in isolation (30-50\% of cases; Daily et al. 2000). Affects 2-3\% of the population, most of whom have mild ID. The DSM-IV category of mental retardation has been renamed to intellectual disability in DSM-V. 
Table 1 (continued)

Epilepsy-aphasia Group of epilepsy syndromes characterized spectrum disorders centrotemporal area that begin in childhood and disappear after puberty. Linguistic, cognitive and behavioural impairments develop concurrently with the seizures. In mild forms of the disorder, such impairments resolve completely after remission of seizures. In severe forms, individuals may be left with a severe and permanent language disorder and other impairments of cognitive functioning. Includes Landau-Kleffner syndrome and ECSWS (epileptic encephalopathy with continuous spikeand-wave during sleep) at the severe end, IEAD (intermediate epilepsy-aphasia disorder) in the middle, and BECTS (benign childhood epilepsy with centrotemporal spikes) at the mild end.

(Table 1). Here, we refer to them collectively as developmental communication disorders, although we recognize that various different diagnostic groupings and terminologies have been applied over the years; even now there is still not a full consensus across the field over how such disorders should be defined, clustered and named (Bishop 2014).

Different communication disorders are characterized by different profiles of impairment (Table 1). For example, childhood apraxia of speech (CAS) is defined as a primary deficit in programming the motor sequences which produce speech, while specific language impairment (SLI) typically involves impaired acquisition of vocabulary and syntax, and dyslexia is diagnosed based on reading/spelling difficulties that occur against a background of overtly normal spoken language. Yet at the behavioral level, there are rarely clear-cut boundaries between different speech and language disorders, between 'language-specific' disorders and those that impact a broader range of cognitive functions, or between disorder and the lower range of normal ability (Pennington and Bishop 2009; Bishop 2010). This is partly because disorders are diagnosed based on psychometric testing and clinical observations of communicative abilities, in which there is no absolute dividing line between normal and abnormal performance. Furthermore, each child has a unique profile of deficits, which changes as the child develops, so there may be no single diagnostic label which perfectly captures the difficulties of an individual. Indeed, high levels of comorbidity have been documented for most of the disorders discussed here. A lack of clear distinctions between disorders is intrinsic to the subject under investigation: speech, language and reading largely draw on shared cognitive processes, and are interwoven with other cognitive systems that are not specific to language.

Moreover, communication abilities are central to all aspects of educational and social development. It may therefore be unreasonable to expect 'pure' disorders with narrow, consistent phenotypes.

It is also worth noting that research into the genetic basis of developmental communication disorders has focussed predominantly on children of European ancestry growing up learning English. It is important to increase the amount of research conducted in other populations, for at least two reasons. First, some DNA variants occur at different frequencies in different populations, which may affect the prevalence of language disorders. For instance, unusually high rates of SLI have been observed on Robinson Crusoe island, which might be explained by a founder effect in this isolated Chilean population (Villanueva et al. 2011). Non-European populations carry a number of unique genetic variants not found in Europeans, some of which might contribute to risk of language-related problems. A recent example is the report of a deletion in TM4SF20 in southeast Asian populations implicated in language delay and cerebral white matter hyperintensities, probably via production of a toxic protein (OMIM 615432) (Wiszniewski et al. 2013). Second, languages are diverse in their phonology and syntax (Evans and Levinson 2009), and also in their orthographic systems, which leads to different manifestations of disorders such as SLI and dyslexia (Leonard 2014; Richlan 2014). Novel types of disorder may be found in languages that have typological features not found in English, such as lexical tone (Wong et al. 2009). Investigation of impairment in sign language offers an interesting opportunity to identify language deficits dissociated from speech (Mason et al. 2010).

\section{Normal Variation and Exceptional Abilities}

The significance of inter-individual variation in linguistic abilities in the non-language-impaired population has only recently come to the fore in linguistics research, which has tended to focus on identifying those aspects of language acquisition and processing that are universal (Fisher and Vernes 2015). Some of this variation is due to environmental factors, and to stochastic effects in neurodevelopment, but multiple studies using twins and adoptees have shown that a large proportion of the variation is heritable (Stromswold 2001; Christopher et al. 2013). There is, for example, heritable variability in the developmental trajectories of spoken and written language acquisition, in the ultimate level of attainment in parameters such as vocabulary size, and in the aptitude for language learning after childhood. A few studies in recent years have examined the influence of putative genetic risk variants for language disorders on linguistic ability in healthy individuals (Whitehouse et al. 2011a; Scerri et al. 2011; Paracchini et al. 2008; Paracchini 2011). However, normal variation in language abilities also has the potential 
to be a novel source of insights into the genetic foundations of speech and language, an avenue that is only just beginning to be explored with genome-wide association studies (GWAS) (Harlaar et al. 2014; St Pourcain et al. 2014a).

Finally, in the future, insights into the genetic underpinnings of language may be gained from focusing on the upper end of the ability spectrum - children who are particularly successful in the acquisition of spoken and written language, and adults who have superior linguistic abilities. Such individuals may have reciprocal patterns of alleles to those with language disorders, thus comparing the two ends of the ability spectrum could add power to genetic studies. There are also intriguing cases of individuals with truly exceptional skills such as hyperlexia and polyglotism, often in the context of ASD and alongside impairments in other cognitive domains (Smith and Tsimpli 1995) - these individuals are an untapped resource for genetic studies.

\section{Paradigms in the Genetic Investigation of Developmental Communication Disorders}

The Genetic Architecture of Developmental Communication Disorders

Following on from the completion of the human genome sequencing project, large-scale efforts over the last decade have sought to comprehensively describe the molecular genetic variation that exists in general population samples across the world. The human genome includes several million single-nucleotide polymorphisms (SNPs) with minor allele frequencies of greater than $1 \%$. These represent common variants which arose thousands of years ago, prior to the dispersal of human populations. In addition, every individual carries thousands of rare variants which have arisen more recently. Remarkably, each individual also carries around 50-100 de novo mutations, which are variants that are not present in either parent but arose during oogenesis or spermatogenesis. The sequencing studies which have uncovered these de novo variants highlight that novel mutations can occur anywhere in the genome (although some mutations might result in prenatal lethality and hence may never be observed in the human population).

On top of these single nucleotide variants (SNVs), there are insertions or deletions of small numbers of nucleotides, and structural variations in chromosomes involving deletions or duplications of thousands or millions of nucleotides, known as copy number variations (CNVs). Even balanced translocations, in which parts of different chromosomes are exchanged without loss of genetic material, are occasionally found in generally healthy individuals. All of these types of genetic variation may potentially contribute to normal variation in communicative abilities and to developmental communication disorders. More severe forms of disorder may also involve gross chromosomal abnormalities, such as aneuploidy, unbalanced translocations and large CNVs (van Bokhoven 2011).

Each developmental communication disorder, as currently defined, is an umbrella term which encompasses not only a good deal of phenotypic variability, but also considerable genotypic variation. In common with other continuous traits, linguistic abilities (and the disorders which affect them) are likely to have a heterogeneous genetic architecture. For example, in some cases, speech and language impairments are classical Mendelian disorders caused by a single, rare, fully-penetrant variant of large effect (Lai et al. 2001). Common forms of disorder with nonMendelian inheritance could alternatively result from the additive effects of a large number of common variants, each with an individually tiny effect on the phenotype in question (Plomin et al. 2009, 2013). Probably the most typical scenario is that disorder occurs as the product of multiple rare and common variants with varying individual effect sizes that combine to determine a level of risk, which is then modulated by environmental influences and random processes in neurodevelopment (Mitchell 2007, 2012). The overlapping deficits and high level of comorbidity observed among different communication disorders mean that distinct conditions may sometimes represent alternative manifestations of the same genetic risk variants. Therefore, in addition to the situation where one phenotype corresponds to many genotypes, we can also expect that one genotype corresponds to multiple phenotypes.

Table 2 outlines the range of experimental paradigms that have been applied to molecular studies of developmental communication disorders to tackle their heterogeneous genetic architecture and make best use of available resources (Newbury and Monaco 2010; Kang and Drayna 2011; Deriziotis and Fisher 2013; Newbury et al. 2014). This research field is at a relatively early stage of development and studies need (when possible) to take an unbiased genomewide approach to gene-hunting. It can be difficult to establish robustly phenotyped collections (extended families and/or large sets of cases) that are suitable for genome-wide paradigms. Thus, many studies have instead targeted genes that have been suggested, but sometimes not proven, to be risk factors in prior reports. As a consequence, the research field has focused disproportionately on a limited pool of candidate genes. Care must be taken not to overemphasize the importance of these genes, in comparison to pursuing the necessarily ambitious studies required for a fully genome-wide view.

\section{Phenotypes in Genetic Studies of Language}

For genetic studies of rare monogenic disorders, it is usually important to have an unambiguous, dichotomous affection status. When investigating common disorders with a complex genetic basis, it is similarly possible to employ a dichotomous distinction, for example in a case-control study design. 
Table 2 Examples in the genetic investigation of language and disorders

\begin{tabular}{llll}
\hline Presumed genetic & Experimental design & Considerations
\end{tabular}

basis

Any genetic factors Twin study: phenotypes of pairs of monozygotic and dizygotic twins.

Adoption study: phenotypes of adopted children, their adoptive parents and, optionally, their biological parents.

Dominant disorders Linkage using genome-wide genotyping of common polymorphic markers in a large family segregating the phenotype in a dominant fashion (using as many members of the family as possible).

NGS in a family segregating the phenotype in a dominant fashion.

Targeted candidate gene sequencing in proband of a family segregating the phenotype in a dominant fashion and, optionally, additional family members.

Karyotyping (to identify translocations) and array $\mathrm{CGH}$ (to identify $\mathrm{CNVs}$ ) in proband of a family segregating the phenotype in a dominant fashion and, optionally, parents and siblings.

Recessive disorders Linkage combined with targeted sequencing or NGS of affected and unaffected family members of a large consanguineous family.

NGS and array CGH in probands with severe sporadic disorders and their parents.

Severe sporadic disorders caused by a de novo event

Karyotyping (to identify translocations) and array CGH (to identify CNVs) in probands. Data from parents required to confirm a $d e$ novo event.

NGS in probands with severe sporadic disorder and their unaffected parents (and optionally siblings).

Complex traits
Linkage using genome-wide genotyping of common polymorphic markers in multiple nuclear families.
Used to assess heritability of a trait. No DNA sampling (Christopher required. Can control for both pre- and post-natal et al. 2013) environmental influences. Note that heritability is not an intrinsic property of a phenotype nor can it be applied to an individual. It is a statistical description of variance in a given population at a specific time, against a particular background of environmental factors.

No DNA sampling required. Does not exclude pre-natal environmental influences.

Powerful strategy to reduce search space for causal variants. Inexpensive using traditional lowdensity genetic markers. Dichotomous affection status is required. Consideration should be given to reduced penetrance and phenocopy. Linked regions are large (tens of $\mathrm{Mb}$ ) and may contain $>100$ genes, so follow-up sequencing is required to identify the causal variant.

More expensive than traditional linkage, but obviates the need for follow-up sequencing to identify causal variants. Can also be performed in conjunction with traditional linkage to first highlight a genomic region of interest. Multiple rare variants may co-segregate with the phenotype, requiring further investigation. Earlier studies undertook WES as it was cheaper and coding variants are more likely to have a functional effect. There is now a shift to WGS to improve coverage of coding regions and include non-coding regions (Meynert et al. 2014).

Requires previous identification of a gene harboring causal variants. Useful as a follow up to WES results to identify additional cases.

CNVs can also be assessed using genome-wide genotyping data.

Linkage is useful to narrow down the genomic region of interest prior to sequencing candidate genes.

Mutations may be homozygous or compound heterozygous.

CNVs can also be assessed using genome-wide genotyping data. Data from parents required to confirm a de novo event. Deletions of the same gene in unrelated probands support a causal role.

An effective way to identify causal variants, given that (Gilissen et al. 2014) there is on average one coding de novo change per genome. Mutations in the same gene in unrelated probands support a causal role.

Can be carried out using dichotomous affection status, (Fisher and or directly with respect to quantitative measures of the genes of interest. Linkage has low genetic resolution and is best suited for detecting approximate locations of risk genes with relatively large effect sizes. Requires intensive follow-up studies to pinpoint etiological variants in regions of linkage.
(Taipale et al. 2003)

(Petrill et al. 2006)

No examples in disorders yet.

(Lesca et al. 2013)

(Strauss et al. 2006)

(Gilissen et al. 2014)

(Sebat et al. 2007)

DeFries 2002)
(Fisher et al. 1998) communication 
Table 2 (continued)

\begin{tabular}{|c|c|c|c|}
\hline $\begin{array}{l}\text { Presumed genetic } \\
\text { basis }\end{array}$ & Experimental design & Considerations & Selected examples \\
\hline & $\begin{array}{l}\text { GWAS using genome-wide genotyping of } \\
\text { common SNPs (typically } 250,000 \text { to } \\
2,500,000 \text { ) in a large number of individuals. }\end{array}$ & $\begin{array}{l}\text { Ideally }>2000 \text { samples are required to } \\
\text { compensate for the large numbers of } \\
\text { SNPs being tested, and to account for the } \\
\text { likely small effect sizes of common variants } \\
\text { on genetically complex traits. Can be carried } \\
\text { out as a case-control or continuous-variable } \\
\text { design. Associated SNPs are not necessarily } \\
\text { functional variants, which may be up to tens } \\
\text { or hundreds of kb away, depending on } \\
\text { linkage disequilibrium structure. }\end{array}$ & (Harlaar et al. 2014) \\
\hline & $\begin{array}{l}\text { Array CGH to identify CNVs in groups of } \\
\text { affected and unaffected individuals. }\end{array}$ & $\begin{array}{l}\text { Comparisons can be made between affected } \\
\text { and unaffected siblings or between groups } \\
\text { of unrelated individuals to determine relative } \\
\text { burden of CNVs between the different groups. }\end{array}$ & (Girirajan et al. 2011) \\
\hline & $\begin{array}{l}\text { Candidate gene association study - genotyping } \\
\text { of common SNPs (typically }<50 \text { ) in } \\
\text { candidate genes, typically in hundreds of } \\
\text { individuals. }\end{array}$ & $\begin{array}{l}\text { Requires previous identification of variants } \\
\text { associated with a trait harboring causal } \\
\text { variants. Can be done as a case-control } \\
\text { or continuous-variable design. }\end{array}$ & (Becker et al. 2014) \\
\hline & $\begin{array}{l}\text { Genome-wide data (genotyping or sequencing) } \\
\text { on a genetically-isolated community with } \\
\text { high incidence of disorder. }\end{array}$ & $\begin{array}{l}\text { Could be a founder mutation, or enrichment } \\
\text { of common risk variants. }\end{array}$ & $\begin{array}{l}\text { (Villanueva et al. } \\
\text { 2011) }\end{array}$ \\
\hline
\end{tabular}

$N G S$ next generation sequencing, WES whole exome sequencing, $W G S$ whole genome sequencing, $C G H$ comparative genomic hybridization, $C N V$ copy number variant, $S N V$ single nucleotide variant, GWAS, genome-wide association study

However it can sometimes be preferable to use quantitative measures to characterize affected individuals and their unaffected relatives, with the potential to also apply these across different related disorders, and even in unselected population cohorts (Carrion-Castillo et al. 2013; Newbury et al. 2014; Paracchini 2011). Quantitative measures circumvent problems arising from variations in diagnostic criteria. In addition, for studies of linguistic skills, use of such measures can be useful for capturing the continuous nature of variation between normal and clinical populations. Quantitative measures include psychometric tests that aim to target sub-skills of verbal and non-verbal cognition. For children who are too young for such testing, questionnaires completed by parents can provide useful quantitative data (Whitehouse et al. 2011b).

A key approach to characterizing communication disorders for genetic studies is to employ endophenotypes - heritable traits that could act as markers for a given condition and that are hypothesized to be closer to the underlying biology. Endophenotypes for communication disorders can be behavioral measures, such as performance on psychometric tests, or neurobiological measures of brain structure or activity. A widely-used endophenotype for language impairment is the nonword repetition task, in which subjects are asked to repeat a pronounceable but meaningless string of speech sounds. This task has been suggested to represent a measure of phonological short-term memory, but performance in the task is also correlated with various other linguistic measures, suggesting that performance in tasks such as nonword repetition may be influenced by nearly as broad a range of cognitive processes as a surface phenotype like language impairment.

Neurobiological endophenotypes can be captured by an array of non-invasive neuroimaging techniques, including magnetic resonance imaging (MRI), electroencephalography (EEG) and magnetoencephalography (MEG). Differences in brain anatomy and activity have been observed in individuals with various language and reading impairments (Watkins 2011; Eicher and Gruen 2013). Neurobiological variation has also been documented among normally-performing individuals, including in the anatomy of language-related brain structures and in the activation patterns during language processing, such as the degree and direction of language lateralization (Tanner and Van Hell 2014; Mazoyer et al. 2014; Thiebaut de Schotten et al. 2011). It may therefore be possible to make connections between genetic variation, brain structure and function, and linguistic performance. Interestingly, several studies have reported evidence that some of the putative risk variants for language-related disorders have detectable effects in the brains of unaffected individuals (Scerri et al. 2012; Pinel et al. 2012; Whalley et al. 2011; Dennis et al. 2011; Tan et al. 2010; Scott-Van Zeeland et al. 2010; Kos et al. 2012; Darki et al. 2012), but see Hoogman et al. 2014. Neurobiological endophenotypes may enable identification of components of the genetic infrastructure underlying language that cannot be discovered using only behavioral measures. The effects of some of the gene variants which modulate the development of language-related circuitry may be dampened or masked at 
the behavioral level due to neural plasticity - such plasticity is known to compensate for trauma to the normal language processing centres if this occurs during development (Moosa et al. 2013). However, the impact of these genetic variants might still be apparent through their effects on neuroanatomy or on brain activity patterns during language processing.

Studies using neurobiological measures have so far been limited by small sample sizes, which reduce power and increase the rate of false-positive findings (Ioannidis 2005). As such, independent replication is essential, but has so far been lacking (Hoogman et al. 2014). Nonetheless, neurobiological endophenotypes hold great promise for bridging genetics and behavior. It is already feasible to robustly investigate relationships between genetic variants and some aspects of brain structure via large-scale neuroimaging genomics studies in thousands of participants (Thompson et al. 2014), while analysis of brain function on this kind of scale represents a major hurdle for the future (Fisher 2015).

Interpreting the Relevance of Genetic Variation to Phenotypic Variation

Microarray technology and next-generation sequencing permit the rapid acquisition of comprehensive genetic information from large numbers of individuals, but the interpretation of these data in relation to language phenotypes remains challenging (Deriziotis and Fisher 2013; Cooper and Shendure 2011). Given that we know little about the relevant biology at this point, one difficulty is the lack of clear a priori candidate genes. Prioritisation of candidates is aided by the growing knowledge of genes mutated in other neurodevelopmental disorders, together with information from databases of protein expression and function, such as the human proteome map (Kim et al. 2014). Nevertheless, studies of human genetic disease continue to uncover causal variants in unexpected genes.

A second difficulty is identifying disorder-related variants against the very high background of incidental variation found in each person's genome (Cooper and Shendure 2011). Most studies prioritize variants affecting protein-coding sequences because they are more likely to have a biological effect, and their functional impact appears easier to predict. But even though the effect of a variant on protein sequence can readily be predicted in silico, and truncating or frameshift mutations (which often dramatically alter the structure of the protein) can reasonably be assumed to be deleterious to protein function, we do not yet have a complete overview of how many copies of each gene are required for normal development. That is, heterozygous protein-damaging variants (those that affect only one gene copy) might still have little consequence at the cellular, tissue or organism level, if the intact gene copy is sufficient for normal function. Moreover, in any given protein many single-residue changes will be tolerated individually.
Software tools such as SIFT and Polyphen-2 use publically available biochemical and evolutionary data to make bioinformatic predictions about whether a missense variant is likely to be pathogenic ( $\mathrm{Ng}$ and Henikoff 2003; Adzhubei et al. 2010). However, these tools have moderate sensitivity and low specificity - one study found that $31-32 \%$ of pathogenic variants were predicted to be benign, while $84-87 \%$ of benign variants were predicted to be pathogenic (Flanagan et al. 2010; Dorfman et al. 2010). More accurate assessments may be gained by considering each variant in the context of the three-dimensional structure of the protein (Venselaar et al. 2013; Preeprem and Gibson 2014).

Ultimately, empirical work is required to properly determine the effects of variants on protein function. Proteins have diverse functions in cells, for example, they are essential for synthesis and release of neurotransmitters and they form the ion channels which mediate neuronal firing. Because every protein has a unique function, studies of protein activity are intrinsically low-throughput and designing appropriate assays requires prior knowledge of the normal activities of the protein. The more that is known about the protein, the more aspects of its function can be examined, and hence a more complete picture of the effect of a variant on protein function can be gained. Most proteins that have so far been implicated in language phenotypes (including FOXP2, the most well known of these) were virtually uncharacterized at the time of discovery. Where available, knowledge on related proteins can help design assays for uncharacterized proteins. Once effective assays have been devised for a particular protein, they can be applied in the future to assess the contribution of a novel variant to a person's phenotype. Such work is important to avoid misattributing a causal role to a variant just because it occurs in a well-known protein (Guidugli et al. 2014).

It remains extremely difficult to judge the importance of non-coding variants that are identified in genomic screening (Deriziotis and Fisher 2013; Cooper and Shendure 2011). Non-coding DNA makes up over $98 \%$ of the genome and generally harbors more variation than coding DNA because it is not under such strong purifying selection, although around 3-4 \% of non-coding DNA is highly conserved and shows evidence of selection, suggesting that these regions may have conserved roles in regulating gene expression. Variants in non-coding DNA can cause disease through misregulation of gene expression, and may account for a large proportion of normal phenotypic variation (Makrythanasis and Antonarakis 2013; Kilpinen and Dermitzakis 2012). Though the precise location and mechanism of action of most regulatory elements remains unknown, a wealth of informative data is now available from sources such as the ENCODE project and RegulomeDB, and advances in techniques such as genome editing are increasing our ability to experimentally investigate non-coding variation (Boyle et al. 2012; Kim and Kim 2014). 


\section{Progress in the Genetic Understanding of Developmental Communication Disorders}

\section{Childhood Apraxia of Speech}

The first gene implicated in a developmental communication disorder was discovered through studies of a large UK pedigree, known as the KE family, in which approximately half of the individuals are affected by CAS (Table 1), accompanied by difficulties in expressive and receptive language abilities, affecting both oral and written language (Watkins et al. 1999; Fisher et al. 1998; Fisher and Scharff 2009). Affected members of the family carry a heterozygous missense mutation in the FOXP2 gene, which encodes a transcription factor that regulates expression of other genes (Lai et al. 2001). Several additional cases of CAS related to FOXP2 haploinsufficiency have been reported (Feuk et al. 2006; Zeesman et al. 2006; Lennon et al. 2007; Shriberg et al. 2006; MacDermot et al. 2005; Turner et al. 2013; Laffin et al. 2012; Rice et al. 2012; Palka et al. 2012). The cellular and neurobiological functions of FOXP2 have been explored using a range of in vitro and in vivo approaches (see Bridging the gap between genes and language: FOXP2 as a case study).

Only a small proportion of cases of CAS are due to FOXP2 mutation, but it is difficult to estimate the precise proportion since most published studies have looked at only a handful of cases. One screen of 49 probands identified a single causal variant in FOXP2 (MacDermot et al. 2005). Other genes that may act as risk factors in CAS include BCL11A, which encodes a transcription factor with a well-characterized role in regulating hemoglobin expression. BCL11 A has also been implicated in controlling neurite outgrowth in cooperation with CASK, a protein mutated in cases of ID (Sankaran et al. 2010; Kuo et al. 2009, 2010a, b). A hemizygous de novo deletion in BCL11A was found in a child with CAS and dysarthria, general oral and gross motor dyspraxia, hypotonia, expressive language delay and mild intellectual delay (Peter et al. 2014). Larger de novo deletions including BCL11A and adjacent genes have been reported in children with language problems alongside skeletal and organ defects (Hancarova et al. 2013).

Deletions of the $E R C 1$ gene on 12p13.3 were described in nine unrelated patients with delayed speech development, most of whom had a diagnosis of CAS (Thevenon et al. 2013). In another report, three affected siblings with CAS, cognitive abnormalities and minor malformations were found to carry an unbalanced 4q;16q translocation (Shriberg et al. 2008). Microdeletions in 16p11.2 may also increase the risk of CAS (Newbury et al. 2012; Raca et al. 2013). CAS has sometimes been observed as a feature associated with a known genetic syndrome. For example, CAS has been estimated to affect $\sim 24 \%$ of people with the rare metabolic disorder, galactosemia (OMIM 230400), which is caused by homozygous or compound heterozygous mutation of the
GALT gene (Shriberg et al. 2011). CAS with normal intellectual performance was reported in one patient with an atypical manifestation of cri du chat syndrome (deletion of $5 \mathrm{p} 15.2-$ p15.3, OMIM 123450) (Marignier et al. 2012). Exome sequencing and studies of CNVs may reveal additional candidate genes for CAS (Worthey et al. 2013; Laffin et al. 2012).

CAS is sometimes regarded as a type of speech sound disorder (SSD), but SSD has also been viewed as a separate disorder, or one which may be related to SLI. The difficulty in classifying SSD arises partly because it can include both articulatory and phonological deficits (see Table 1). The presence of phonological deficits has also suggested etiological overlap with dyslexia, and some genomic regions linked to dyslexia have shown linkage to SSD (Newbury and Monaco 2010). Additional genomic loci in SSD have been identified more recently, but no candidate genes have been pinpointed within any of the reported linkage intervals (Peter et al. 2012).

\section{Stuttering}

Linkage studies for persistent stuttering (see Table 1) conducted in several different populations have implicated multiple genomic loci and different modes of inheritance (Kang and Drayna 2011; Raza et al. 2012, 2013; Domingues et al. 2014). A linkage study in a large consanguineous Pakistani family led to the identification of a linkage peak on chromosome 12 (Kang et al. 2010). Sequencing of all the genes in this region identified a missense mutation (E1200K) in the GNPTAB gene. The same mutation was found in affected members of several other Pakistani families. Subsequent targeted sequencing in unrelated individuals of Asian and European descent uncovered further missense variants in GNPTAB, and in the related genes GNPTG and NAGPA (Kang et al. 2010). The same research team recently reported an excess of rare coding variants in GNPTAB and NAGPA (although not in GNPTG) in an expanded sample of stuttering cases (Han et al. 2014), but further independent replication studies are needed to determine the overall contribution of mutations in these genes to the etiology of developmental stuttering.

GNPTAB, GNPTG and NAGPA encode enzymes involved in the mannose-6-phospate pathway for lysosomal enzyme targeting (Coutinho et al. 2012). It is perhaps surprising that such a fundamental metabolic pathway should be involved in a relatively specific disorder like stuttering. Indeed, mutations in these genes are known to cause severe recessive metabolic disorders. Mutations in GNPTG cause mucolipidosis III $\gamma$ (OMIM 252650), whereas mutations in GNPTAB cause mucolipidosis II $\alpha / \beta$ (OMIM 252500) and the less severe mucolipidosis III $\alpha / \beta$ (OMIM 252600). All three disorders include skeletal, cardiac and other defects. Patients with mucolipidosis II typically show developmental delay and ID, whereas those with mucolipidosis III have normal intelligence or mild cognitive impairments. The variants identified 
in individuals with stuttering are different from those implicated in mucolipidosis and probably have less severe effects on protein function - individuals homozygous for the E1200K mutation in GNPTAB do not show features of mucolipidosis. Functional characterization has been performed for three missense variants in NAGPA identified in stuttering cases, which demonstrated reduced enzymatic activity, supporting their etiological significance (Lee et al. 2011).

\section{Specific Language Impairment and Dyslexia}

SLI is perhaps the most common developmental disorder affecting spoken language skills, and typically involves problems that also extend to the written domain (Table 1). Dyslexia, by contrast, is defined as isolated difficulties in reading and/or spelling without obvious impairments in spoken language. Nevertheless, many children with dyslexia have been shown to display subtle deficits in phonological skills that may (at least in part) account for their difficulties with written language. Both SLI and dyslexia are diagnosed on the basis of excluding explanatory factors. Thus, these disorders are by nature heterogeneous in severity and in the observed profile of deficits, which might change as a child develops. Language impairments and reading/spelling difficulties show high levels of comorbidity, which suggests a possible common genetic etiology (Pennington and Bishop 2009). The initial leads in unravelling the genetic basis of these disorders came from linkage studies first reported over 15 years ago, which mapped several genomic loci that might contain risk genes (CarrionCastillo et al. 2013; Newbury and Monaco 2010; Fisher and DeFries 2002). Linkage studies highlight broad chromosomal intervals containing many different genes. Two complementary approaches have been used to pinpoint the most promising candidate genes within these linkage regions. One method involves association screening of polymorphic markers within the target interval. This kind of work led to the identification of putative risk SNPs in KIAA0319, DCDC2, and MRPL19/ $C 2 O R F 3$ in dyslexia, and in CMIP and $A T P 2 C 2$ in SLI (Francks et al. 2004; Meng et al. 2005; Anthoni et al. 2007; Newbury et al. 2009). The second method relies on observations of affected cases or families with chromosomal rearrangements disturbing a known region of interest. For example, mapping of rare translocation breakpoints in dyslexia implicated the genes $D Y X 1 C 1$ and $R O B O 1$ as candidates for the disorder (Hannula-Jouppi et al. 2005; Taipale et al. 2003).

A large number of subsequent studies have tested these candidate genes for association with affection status or with various psychometric measures, in cohorts with the same disorder as the original linkage cohort, or with the other of the two disorders (Carrion-Castillo et al. 2013). Association with quantitative measures in general population cohorts has also been investigated (Paracchini et al. 2008, 2011; Scerri et al. 2011). Results have been mixed, with some studies reporting evidence of association while others do not. This outcome may partly be due to the arbitrary threshold of statistical significance applied in the studies, as well as difficulties in correcting for multiple testing, and it is possible that a subset of the original findings first implicating these candidates represent false-positives (Carrion-Castillo et al. 2013; Newbury et al. 2014). It is also debatable whether a finding of association with a different phenotype, or with the opposite direction of effect, represents a replication (Newbury et al. 2014). A recent large association study for four major candidate genes - KIAA0319, DCDC2, MRPL19/C2ORF3 and $D Y X 1 C 1$ - across eight dyslexia cohorts did not find any associations that were significant across all cohorts (Becker et al. 2014). Thus there has been a need for a fresh look for candidate genes.

To this end, novel loci of interest have recently been suggested by new linkage screens and the first GWAS in SLI, dyslexia and general population cohorts, and replication should be sought for these loci (Bartlett et al. 2014; Field et al. 2013; Nudel et al. 2014; Luciano et al. 2013; Harlaar et al. 2014; Eicher et al. 2013; Gialluisi et al. 2014). These studies have highlighted the absence of single common variants of large effect on language-related phenotypes. The way forward is therefore to seek larger sample sizes for GWAS studies, but also to consider the effects of rare variants, which have been found to be important in other neurodevelopmental conditions (see section on Intellectual disability and autism spectrum disorders below). A small number of families with potentially monogenic language-related syndromes have also been reported, suggesting that there is still a place for Mendelian disorders in illuminating the genetic foundations of language (Briscoe et al. 2012; de Kovel et al. 2004; Peter et al. 2012, 2013; Addis et al. 2010).

An alternative to genome-wide screening is to select candidate genes based on their involvement in molecular networks already known to be disrupted in communication disorders. FOXP2 has not been directly implicated in other communication disorders beyond CAS, underlining the specificity of the phenotype resulting from FOXP2 disruptions (Newbury et al. 2002; Han et al. 2014; Toma et al. 2013). However, given that it is a transcription factor, genes regulated by FOXP 2 could have roles in other forms of language disorder. Several studies have together identified thousands of genes that are potentially regulated by FOXP2 in at least one tissue or developmental timepoint (Spiteri et al. 2007; Vernes et al. 2007, 2011; Konopka et al. 2009). One early study (Vernes et al. 2008) chose to follow up specifically on CNTNAP2, which encodes a neuronal cell-surface transmembrane protein. A complete absence of CNTNAP2 protein (also known as CASPR2) causes a syndrome of childhood-onset focal epilepsy leading to language regression, severe ID, and social and behavioral problems (OMIM 610042), with many aspects of the phenotype mirrored in Cntnap2-deficient mice 
(Strauss et al. 2006; Zweier et al. 2009; Penagarikano et al. 2011). Common SNPs across CNTNAP2 were tested for association with quantitative language measures in families with SLI, which revealed association with a cluster of intronic SNPs (Vernes et al. 2008). These same variants have been associated with language measures in other samples, and there is also evidence that heterozygous loss-of-function mutations and common SNPs in CNTNAP2 represent a risk factor for neurodevelopmental disorders (Whitehouse et al. 2011a; Luciano et al. 2013; Rodenas-Cuadrado et al. 2014).

Most of the candidate risk SNPs identified so far for SLI and dyslexia have been located in non-coding regions of the genome. This poses a challenge for functional investigations aimed at gaining insights into the molecular mechanisms underpinning disorder because the biological role of much non-coding DNA is poorly understood, making it hard to design appropriate assays. An additional important consideration when designing experiments to probe the effects of noncoding variation is that a variant showing association with a phenotype is not necessarily responsible for that phenotype because a number of nearby variants will be in linkage disequilibrium (will be inherited together). Nonetheless, several studies have reported potential effects of non-coding variation on gene expression (Anthoni et al. 2007; Paracchini et al. 2006; Dennis et al. 2009; Tran et al. 2014; Peschansky et al. 2010; Hannula-Jouppi et al. 2005). For example, a SNP in the promoter of KIAA0319 that showed association with dyslexia reduced gene expression in an in vitro assay and created a binding site for the transcriptional repressor POU2F1 (Dennis et al. 2009). Approaches that combine genetic association with experimental investigations in in vitro and in vivo models will be vital to understanding the role of non-coding variation in neurodevelopment.

The protein products of the genes harboring candidate risk variants for SLI and dyslexia were largely uncharacterized at the time when they were first associated with these disorders. Research examining the basic biology of these proteins has led to some interesting discoveries. For example, DYX1Cl has been shown to play a role in the primary cilium and mutations of this gene are now known to cause a monogenic form of the disorder primary ciliary dyskinesis (Carrion-Castillo et al. 2013; Tarkar et al. 2013). In utero gene knockdown in rats has been a major strategy for examining the role of dyslexia candidate genes in brain development (Szalkowski et al. 2012; Threlkeld et al. 2007; Gabel et al. 2011). These experiments have consistently produced deficits in neuronal migration that were intriguing in the light of an early report of heterotopias in postmortem brains from individuals with dyslexia (Galaburda et al. 1985). However, such results should be viewed with caution because migration deficits from in utero knockdown in rats do not appear to be supported by investigations in other systems, such as gene knockouts in mice (e.g., see Wang et al. 2011) and there is new evidence suggesting that the knockdown methodology is susceptible to off-target effects (Baek et al. 2014). Effects of risk variants on human brain anatomy and function have also been suggested by imaging and electrophysiological studies, although (as noted above) sample sizes for the relevant studies have been small and underpowered, so independent replication is still needed (Scerri et al. 2012; Pinel et al. 2012; Cope et al. 2012; Lamminmaki et al. 2012; Whalley et al. 2011; Dennis et al. 2011; Tan et al. 2010; Scott-Van Zeeland et al. 2010; Kos et al. 2012; Darki et al. 2012).

\section{Intellectual Disability and Autism Spectrum Disorders}

Linguistic abilities, general cognitive abilities and social cognition are highly inter-related, both during development and in some accounts of language evolution. General cognitive ability is highly heritable, but GWAS studies have struggled to find significant effects for common variants, nor has any association been found with low-frequency CNVs (Davies et al. 2011; McRae et al. 2013; Kirkpatrick et al. 2014). GWAS studies for social behavior have faced similar difficulties (Ebstein et al. 2010; St Pourcain et al. 2013, 2014b). However, a GWAS for educational attainment in over 100,000 individuals identified three SNPs which reached genome-wide significance, and these associations were replicated in a further sample of 25,000 individuals (Rietveld et al. 2013), illustrating that very large sample sizes do have the power to detect small contributions from common SNPs to normal phenotypic variation.

A complementary approach for uncovering the genetic basis of these cognitive faculties has been to look at disorders in which they are disrupted, namely ID, an impairment in general cognitive ability, and ASD, in which deficits in social interaction and communication are a defining feature (Table 1). ID and ASD are highly comorbid (Brereton et al. 2006; Matson and Shoemaker 2009), and there is a large degree of variation in the profile of language skills within each class of disorder. Language is often relatively preserved in cases of mild ID (IQ of 50-70). Individuals with ASD in the absence of ID may develop fluent language, but often with deficits in pragmatic aspects of language comprehension in addition to impaired use of language in social interaction. These milder forms of ID and ASD border on normal variation, and an additional category of pragmatic language impairment has been proposed for individuals who show the linguistic deficits characteristic of ASD but without the repetitive behaviors (Gibson et al. 2013). Mild forms of ID and ASD appear to have a complex genetic basis, possibly with significant contributions from environmental influences (Gaugler et al. 2014; van Bokhoven 2011).

In contrast, language is usually highly impaired or absent in individuals with moderate-to-severe ID, with or without features of ASD. Children affected by severe ID and/or ASD are 
generally born to healthy parents, and accordingly de novo chromosomal translocations and aneuploidy are major causes of these disorders (van Bokhoven 2011). Other modes of inheritance consistent with sporadic disorder are autosomal recessive, X-linked, and imprinting, and examples of all of these are also found for severe ID (des Portes 2013; Musante and Ropers 2014; Buiting 2010). Recently, sequencing of probands and parents has confirmed that single de novo protein-altering mutations are also causal in a significant proportion of cases (Gilissen et al. 2014; Krumm et al. 2014; Veltman and Brunner 2012). ID sometimes occurs in the context of a syndromic disorder, in which there are co-occurring developmental defects in other organs (van Bokhoven 2011). In many cases these syndromes are known to result from single point mutations, or deletions affecting certain genes. Since genes frequently have pleiotropic roles in the development of multiple organ systems, disorders in which linguistic and other cognitive deficits occur alongside physical abnormalities may be no less informative about the genetic underpinnings of language than supposedly language-specific disorders. For example, the importance of FOXP2 in brain circuits involved in speech and language is not diminished by the fact that it also plays key roles in lung development (Shu et al. 2007).

Etiological mutations that cause ID and/or ASD have been found in a large number of different genes, confirming that these are not monolithic disorders, but umbrella terms for a large collection of genetically-distinct entities. New monogenic ID and ASD syndromes are continuously being discovered, and some of these reveal specific molecular links between ID/ ASD and more language-specific disorders. Two recentlydiscovered syndromes are caused by haploinsufficiency of transcription factors that are known to directly interact with FOXP2 (Li et al. 2004; Sakai et al. 2011; Deriziotis et al. 2014). One syndrome results from mutations of FOXP1, a paralog of FOXP2 which shows partially overlapping expression in brain regions including the striatum (Ferland et al. 2003). The other syndrome results from mutations in $T B R 1$, which is involved in cortical development and is co-expressed with FOXP2 in layer 6 of the cortex (Hevner et al. 2001; Willsey et al. 2013). Both syndromes are characterized by global developmental delay, ID, speech delay and varying degrees of language deficits (O'Roak et al. 2011; Traylor et al. 2012; Palumbo et al. 2013; Palumbo et al. 2014; O'Roak et al. 2012; Belengeanu et al. 2014; Le Fevre et al. 2013; Bacon and Rappold 2012). In addition, autistic behaviors are found in all cases with TBRI disruptions and in some individuals with FOXP1 mutations. The language deficits in the distinct disorders caused by disruptions in FOXP1, TBR1 and FOXP2 may relate to dysregulation of common downstream targets as a result of loss of protein-protein interactions. This hypothesis is supported by the fact that pathogenic mutations that disrupt the TBR1 protein result in loss of interaction with FOXP2 (Deriziotis et al. 2014).
Studies of common SNPs, rare SNVs and CNVs, in the context of ID and ASD, have together yielded thousands of genes in which variation may contribute differing degrees of risk for the development of these disorders, and/or influence the severity of the disorder (Huguet et al. 2013; van Bokhoven 2011). Among this collection of genes we can attempt to identify biological themes that are useful to narrow the search space for language-related genes, for example in prioritizing variants identified from next-generation sequencing data (Deriziotis and Fisher 2013). Unsurprisingly, synaptic homeostasis is an overarching theme in ID/ASD genetics, including categories of proteins such as ion channels, cell adhesion molecules, signal transduction proteins, and proteins involved in mRNA metabolism and chromatin modification (Huguet et al. 2013; Srivastava and Schwartz 2014; Pinto et al. 2014).

An interesting insight from genetic investigations of ID and ASD is that some genetic lesions cause severe cognitive deficits, whilst leaving language abilities relatively intact. These include the preserved speech or 'Zapella' variant of Rett syndrome (OMIM 312750) which is caused by de novo mutations in the MECP2 gene (Neul et al. 2010). MECP2 is on the $\mathrm{X}$-chromosome, therefore mutations are lethal in males and only females are observed to be affected. In contrast to individuals with typical forms of Rett syndrome, individuals with the preserved speech variant recover some language after regression, despite IQs of $<50$. A second example is Williams syndrome (OMIM 194050) which is caused by hemizygous deletion of 28 genes on 7q11.23 (Pober 2010). Affected individuals have physical abnormalities and a cognitive profile that includes weaknesses in spatial and problem-solving domains, but relative strengths in language. Furthermore, people with Williams syndrome have very sociable personalities, in contrast to individuals with the preserved speech variant of Rett syndrome who display features of ASD. One caveat is worth stressing here. Even in neurodevelopmental disorders where speech and/or language skills appear to be preserved relative to other cognitive domains, neuropsychological studies usually reveal abnormalities as compared to typical age-matched children (Thomas et al. 2009). Further investigation will be needed to clarify the intersections and boundaries of language, sociality and general cognition, and how these relate to genetic factors.

\section{Epilepsy-Aphasia Spectrum Disorders}

It is has been noted that there are connections and overlaps between epilepsy and SLI, dyslexia and SSD (Clarke et al. 2007; Pal 2011). Of particular interest are the epilepsy-aphasia spectrum (EAS) disorders - a group of related epilepsy syndromes of varying severity associated with language impairments (OMIM 245570) (Table 1). EAS is characterized by seizures (bursts of excessive, synchronous cortical neuronal activity) which originate in the centrotemporal area, close to 
cortical regions involved in language processing (Van Bogaert 2013). Seizures begin in childhood and are accompanied by variable regression in language and cognitive abilities and behavioral changes. Language skills may recover after the remission of seizures that occurs in adolescence, or may be permanently impaired. Although the genetic architecture of EAS disorders is still not fully understood, studies have shown that heterozygous disruptions of GRIN2A account for around $10-20 \%$ of cases, including both inherited and de novo occurrences of the disorder (Lesca et al. 2013; Lemke et al. 2013; Carvill et al. 2013; DeVries and Patel 2013). GRIN2A encodes a subunit of the NMDA receptor, a ligand- and voltage-gated cation channel which is central to synaptic plasticity (Fan et al. 2014). Functional analysis of two missense mutations found in patients with EAS has confirmed that these mutations affect the opening and closing of the ion channel (Lesca et al. 2013). Mutations in GRIN2B, a paralog of GRIN2A, are found in patients with ID and/or ASD (O'Roak et al. 2011; Dimassi et al. 2013). GRIN2A and GRIN2B can be interchanged to form a functional NMDA receptor; GRIN2B is expressed during fetal development but is replaced by expression of GRIN2A postnatally (Liu et al. 2004). These findings highlight the importance of the NMDA receptor in brain development and homeostasis.

The SRPX2 gene, located on the X-chromosome, was previously implicated in EAS since a missense variant was found to co-segregate with seizures and CAS in one family (Roll et al. 2006). However, all family members who experience seizures were subsequently found to have a GRIN2A mutation and no further $S R P X 2$ mutations have been reported in EAS (Lesca et al. 2013; Reinthaler et al. 2014). The SRPX2 variant in question is not specific to the family but is a rare variant present in the general European population (Piton et al. 2013). Two members of the family with CAS, but no seizures, carried the SRPX2 variant but not the GRIN2A variant, so a role for SRPX2 in CAS cannot be excluded (Lesca et al. 2013). Because of the well-established contributions of FOXP2 to CAS, it was hypothesized that FOXP2 might regulate $S R P X 2$, and there is some supporting evidence for this link (Roll et al. 2010; Sia et al. 2013). In utero knockdown of Srpx2 in rat cortex resulted in neuronal migration deficits and epileptiform activity (Salmi et al. 2013), but given the possibility of offtarget effects in such knockdown experiments (Baek et al. 2014), knockout mouse models would also aid in understanding the relevance of SRPX2 to brain development.

\section{Bridging the Gap Between Genes and Language: FOXP2 as a Case Study}

As described in the previous section, a number of candidate genes and genetic variants are emerging in relation to human communication. The ultimate aim is to explain how these genes and variants influence communicative abilities through effects on neurodevelopment and brain function. This will require integration of experimental approaches from molecular and cellular biology, animal models and brain imaging. In the case of disorders, functional work is also necessary to establish causality for a particular variant, and can furthermore provide insights into pathogenic mechanisms which might enable therapeutic interventions. Knowledge gleaned from functional work can feed back to gene discovery efforts by highlighting key biological pathways which may harbor additional variants relevant to communication disorders (Fig. 1).

A framework for bridging the gap between genetics and behavior is provided by a decade of research into FOXP2 (Fisher and Scharff 2009; Graham and Fisher 2013). It is still not fully understood why disruption of one copy of this gene should lead to a severe speech and language disorder, but considerable progress has been made in elucidating both molecular-level effects and consequences for higher-level brain function. As a first step towards understanding the pathophysiology of FOXP2-related language disorder, molecular biological studies showed that two different FOXP2 mutations found in language-impaired individuals result in a loss of DNA-binding and transcriptional regulation activity (Vernes et al. 2006). Coupled with the observation of CAS in people with whole gene deletions affecting FOXP2, this indicates that the molecular mechanism of the disorder likely involves FOXP2 haploinsufficiency leading to dysregulation of neural target genes. Several studies have therefore attempted to identify such neural targets. However, there is limited overlap between datasets, and the crucial targets of FOXP2 with regard to language disorder remain unclear (Spiteri et al. 2007; Vernes et al. 2007; Vernes et al. 2011; Konopka et al. 2009). One key set of FOXP2 targets may be those involved in neurite outgrowth. Genes in this category were found to be enriched among putative targets in embryonic mouse brain, leading to the discovery that neurons from mice that completely lack Foxp 2 exhibit reduced neurite outgrowth, which could impair neuronal connectivity in the developing brain (Vernes et al. 2011).

The role of FOXP2 in the development of neural circuitry has been further investigated using several mutant mouse lines (Fisher and Scharff 2009; French and Fisher 2014). Mice lacking functional Foxp2 (the rodent ortholog of human FOXP2) have developmental delays and severe motor impairments, dying at 3-4 weeks after birth (French and Fisher 2014). Mice with one functional copy of Foxp2 are normal or show mild developmental delays, depending on the genomic background, but in-depth investigations have uncovered deficits which may help explain the speech impairments observed in patients with FOXP2-related CAS. In particular, mice heterozygous for the mutation found in the KE family show impaired long-term depression in corticostriatal circuits 
and significant deficits in motor-skill learning (Groszer et al. 2008). Follow-up in vivo electrophysiology studies in awakebehaving mice indicated abnormally high basal activity in medium spiny neurons of the striatum and alterations in striatal plasticity during motor-skill learning (French et al. 2012). Additional studies with mutant mice have highlighted deficits in the processing and integration of auditory information (Kurt et al. 2009; Kurt et al. 2012). In both humans and mice, FOXP2 is expressed in brain regions including the striatum, cerebellum, thalamus and cortex (Ferland et al. 2003; Lai et al. 2003; Fisher and Scharff 2009). The profile of language impairments observed in individuals with FOXP2 disruptions may represent a compound disorder resulting from reduction in levels of this transcription factor in multiple brain areas involved in speech and language. It will therefore be interesting to employ conditional knock-out mice to investigate the consequences of reduced expression in different brain structures in isolation (French et al. 2007).

Several studies have reported on effects of Foxp2 disruption on the ultrasonic vocalizations of mouse pups, but these vocal behaviors are not a good model for human speech and such findings should be viewed with caution (see Fisher and Scharff 2009; French and Fisher 2014 for more extensive discussion). More relevant to speech are investigations of zebra finches, which have addressed potential contributions of FoxP2 (the songbird ortholog of human FOXP2) to vocal learning (Wohlgemuth et al. 2014). In juvenile birds, FoxP2 levels are increased in Area X, a striatal nucleus involved in vocal learning, during the critical period for song-learning (Haesler et al. 2004) and are downregulated when adult males are practising their songs without directing them to a female (Miller et al. 2008; Teramitsu and White 2006; Teramitsu et al. 2010). Furthermore, viral-based knockdown of FoxP2 in Area $\mathrm{X}$ results in reduced spine density of medium spiny neurons (Schulz et al. 2010) and impairs song-learning (Haesler et al. 2007; Murugan et al. 2013). Thus, both investigations of vocal learning in songbirds and of motor-skill learning in mouse models point to roles for FOXP2 in neural plasticity. It is therefore possible that this gene, which has a particularly high level of sequence conservation in vertebrates, has ancient roles in general motor learning that have been co-opted in support of vocal learning in both the human and zebra finch lineages.

Structural MRI studies in the KE family have uncovered subtle abnormalities in several regions of the brain, including the precentral gyrus and Broca's area, the caudate nucleus, and the cerebellum (Vargha-Khadem et al. 1998; Watkins et al. 2002). Intriguingly, there is high concordance between sites of pathology and the regions where FOXP2 is normally expressed (Lai et al. 2003). Furthermore, functional imaging during language tasks has found activation differences in these regions in affected family members (Vargha-Khadem et al. 1998; Watkins et al. 2002; Liegeois et al. 2003; Liegeois et al. 2011). A general issue with brain imaging studies of language-related disorders is that the individuals studied are
Fig. 1 Studies of human variation and comparison with other species yield genes and genetic variants with putative roles in communicative abilities. Molecular and cellular investigations, animal models and brain imaging can be used to evaluate the relevance of these genes and variants in neurodevelopment. Findings from such investigations can highlight biological themes, with the potential to feed back to inform gene discovery efforts. MRI- magnetic resonance imaging; fMRI- functional magnetic resonance imagining; EEG- electroencephalography; MEG- magnetoencephalography; eQTL- expression quantitative trait locus; ENCODEencyclopaedia of DNA elements; GWAS- genome-wide association study; SIFT- sorting intolerant from tolerant

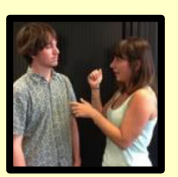

Development

Variation in

communicative

abilities

\section{Candidate genes}

\section{Genetic studies}

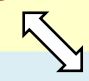

Comparative genomics

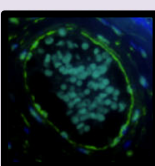

\section{Expression}

Temporal and spatial

expression pattern,

regulatory mechanisms

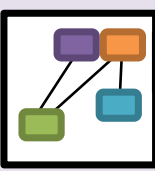

Molecular networks

Protein-protein interactions,

target genes, signalling

cascades, metabolic pathways

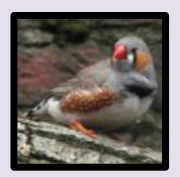

Animal models

Knockout/knockdown:

neuroanatomy,

electrophysiology, behavior

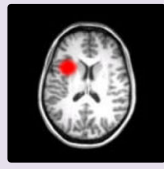

Human brain imaging

Whole-gene association with structural MRI, fMRI, EEG and MEG measures
Candidate variants

Annotation/prediction Allele frequency, conservation, eQTLs, ENCODE, GWAS, effect predictions eg. SIFT

Cell-based assays

Protein expression and stability, activity, molecular interactions

Animal models Mice carrying human variants: neuroanatomy, electrophysiology, behavior

Human brain imaging Variant association with structural MRI, fMRI, EEG and MEG measures
ATGTGTT TCGACTT GGTAGCA AAAGTGC
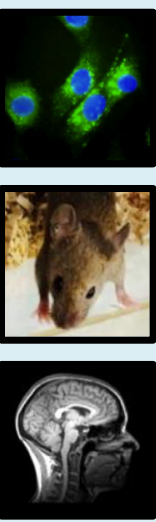
typically adults or older children who have had the disorder for many years. It is therefore difficult to determine if the observed differences in the brain are a cause or an effect of the disorder. The functional activation differences observed in affected members of the KE family may indeed be an effect of the disorder, reflecting a necessary reorganization of language processing pathways. However, because the anatomical differences exist in the context of a single genetically-defined disorder, and overlap with regions of FOXP2 expression, they are more likely to have a developmental origin and to underlie the behavioral deficit. Some reports have suggested that common SNPs in FOXP2 have an effect on brain structure and/or function. However, an association study in $>1300$ people from the general population did not find evidence that common variants of FOXP2 lead to detectable neuroanatomical differences, suggesting that such effects are limited to variants that have marked effects on protein function (Hoogman et al. 2014).

Evolutionarily novel contributions of FOXP2 to human language may have resulted from changes in its temporospatial expression pattern, changes in its downstream targets, or changes in the amino acid sequence of the protein. The expression pattern of this gene is broadly conserved in vertebrates, although it remains possible that there may have been subtle alterations in our lineage (Lai et al. 2003; Ferland et al. 2003; Teramitsu et al. 2004). It is highly likely that there are differences in sets of downstream targets in different species, and that such changes may have been influential in driving evolutionary differences in hominin neurodevelopment, but the crucial changes with regard to language have not yet been clearly identified (Nelson et al. 2013; Konopka et al. 2009). Two amino acid substitutions in FOXP2 occurred in the human lineage since the split from chimpanzees, against a generally low background of amino acid change during vertebrate evolution (Enard et al. 2002; Enard 2011). There is evidence that these substitutions affect target regulation and synaptic plasticity, but the molecular mechanism of these effects is still unknown (Konopka et al. 2009; Enard et al. 2009; ReimersKipping et al. 2011). Interestingly, a selective sweep may have occurred at the FOXP2 locus within the last 200,000 years, but is not explained by the amino acid substitutions and may instead relate to non-coding changes affecting FOXP2 regulation, or may be a false-positive finding (Coop et al. 2008; Maricic et al. 2013; Graham and Fisher 2013).

The molecular networks radiating from FOXP2 may hold additional language-related factors, including proteins and microRNAs regulating FOXP2 expression, FOXP2interaction partners, and genes regulated by FOXP2. Several studies have identified putative members of this FOXP2 molecular network (Coutinho et al. 2011; Clovis et al. 2012; Shi et al. 2013; Spiteri et al. 2007; Vernes et al. 2007; Konopka et al. 2009; Vernes et al. 2011; Li et al. 2004; Chokas et al. 2010; Sakai et al. 2011; Zhou et al. 2008). In previous sections we have discussed the relationship of the FOXP2 target,
CNTNAP2, and the FOXP2 interacting proteins, TBR1 and FOXP1, to communication disorders. However, for most of the molecules in the FOXP2 interaction network, the relevance to speech and language is still to be explored.

\section{Concluding Remarks}

As a research field, the genetics of human communication may still be in its infancy, but the fascinating insights gained so far have opened the way for the necessarily ambitious projects which will follow. When framing research questions about language evolution and development, it is important to incorporate the most current knowledge from a range of fields such as linguistics, evolutionary anthropology, neurobiology, and ethology. Next-generation sequencing offers the chance to obtain large amounts of genetic information, but efforts need to be channelled into computational and experimental methods to identify biologically relevant variants. It remains a challenge to recruit large cohorts of subjects and characterize their language abilities and success will depend on international collaboration between researchers across different disciplines.

The results of these studies could prove to have great significance for science and society. A major area of importance will be in understanding the genetic basis of communication disorders, which are common and have a considerable impact on educational, social, economic and emotional outcomes. A better understanding of underlying risk factors may enable genetic tests for early identification of at-risk children, with the possibility of intervention to ameliorate the effects, as well as more precise diagnosis and optimized educational assistance, a better prediction of long-term outcomes, and a greater understanding in society. In the case of ASD, ID and EAS, genetic studies have already revolutionized our understanding of the etiology of these disorders, and are kick-starting a shift in the approach to diagnosis from phenotype-first to genotype-first (Stessman et al. 2014). Language problems occur not only in the context of neurodevelopmental disorders, but also in neuropsychiatric and neurodegenerative conditions. Therefore, an understanding of the molecular neurobiology of language is of wide clinical impact, and has relevance to a broad range of neuropsychology questions.

Finally, insights into the genetic foundations of human communication will have an impact on all fields of research which touch upon the evolution or prehistory of our species, since the emergence of language is a key theme in the human story.

\section{References}

Addis, L., Friederici, A. D., Kotz, S. A., Sabisch, B., Barry, J., Richter, N., et al. (2010). A locus for an auditory processing deficit and language 
impairment in an extended pedigree maps to $12 \mathrm{p} 13.31-\mathrm{q} 14.3$. Genes, Brain, and Behavior, 9(6), 545-561.

Adzhubei, I. A., Schmidt, S., Peshkin, L., Ramensky, V. E., Gerasimova, A., Bork, P., et al. (2010). A method and server for predicting damaging missense mutations. Nature Methods, 7(4), 248-249.

Anthoni, H., Zucchelli, M., Matsson, H., Muller-Myhsok, B., Fransson, I., Schumacher, J., et al. (2007). A locus on 2p12 containing the coregulated MRPL19 and C2ORF3 genes is associated to dyslexia. Human Molecular Genetics, 16(6), 667-677.

Bacon, C., \& Rappold, G. A. (2012). The distinct and overlapping phenotypic spectra of FOXP1 and FOXP2 in cognitive disorders. Human Genetics, 131(11), 1687-1698.

Baek, S. T., Kerjan, G., Bielas, S. L., Lee, J. E., Fenstermaker, A. G., Novarino, G., et al. (2014). Off-target effect of doublecortin family shRNA on neuronal migration associated with endogenous microRNA dysregulation. Neuron, 82(6), 1255-1262.

Bartlett, C. W., Hou, L., Flax, J. F., Hare, A., Cheong, S. Y., Fermano, Z., et al. (2014). A genome scan for loci shared by autism spectrum disorder and language impairment. The American Journal of Psychiatry, 171(1), 72-81.

Becker, J., Czamara, D., Scerri, T. S., Ramus, F., Csepe, V., Talcott, J. B., et al. (2014). Genetic analysis of dyslexia candidate genes in the European cross-linguistic NeuroDys cohort. European Journal of Human Genetics, 22(5), 675-680.

Belengeanu, V., Gamage, T. H., Farcas, S., Stoian, M., Andreescu, N., Belengeanu, A., et al. (2014). A de novo $2.3 \mathrm{Mb}$ deletion in $2 \mathrm{q} 24.2 \mathrm{q} 24.3$ in a 20 -month-old developmentally delayed girl. Gene, 539(1), 168-172.

Berwick, R. C., Okanoya, K., Beckers, G. J., \& Bolhuis, J. J. (2011). Songs to syntax: the linguistics of birdsong. Trends in Cognitive Sciences, 15(3), 113-121.

Bishop, D. V. (2010). Overlaps between autism and language impairment: phenomimicry or shared etiology? Behavior Genetics, 40(5), 618-629.

Bishop, D. V. (2014). Ten questions about terminology for children with unexplained language problems. International journal of language \& communication disorders / Royal College of Speech \& Language Therapists, 49(4), 381-415.

Bishop D. V., Chan J., Adams C., Hartley J., Weir F. (2000) Conversational responsiveness in specific language impairment: evidence of disproportionate pragmatic difficulties in a subset of children. Developmental Psychopathology, 12(2), 177-99.

Bolhuis, J. J., Okanoya, K., \& Scharff, C. (2010). Twitter evolution: converging mechanisms in birdsong and human speech. Nature Reviews Neuroscience, 11(11), 747-759.

Boyle, A. P., Hong, E. L., Hariharan, M., Cheng, Y., Schaub, M. A., Kasowski, M., et al. (2012). Annotation of functional variation in personal genomes using RegulomeDB. Genome Research, 22(9), $1790-1797$.

Brereton, A. V., Tonge, B. J., \& Einfeld, S. L. (2006). Psychopathology in children and adolescents with autism compared to young people with intellectual disability. Journal of Autism and Developmental Disorders, 36(7), 863-870.

Briscoe, J., Chilvers, R., Baldeweg, T., \& Skuse, D. (2012). A specific cognitive deficit within semantic cognition across a multigenerational family. Proceedings of the Royal Society, B, 279(1743), 3652-3661.

Buiting, K. (2010). Prader-Willi syndrome and angelman syndrome. American Journal of Medical Genetics Part C, 154C(3), 365-376.

Call, J., \& Tomasello, M. (2008). Does the chimpanzee have a theory of mind? 30 years later. Trends in Cognitive Sciences, 12(5), 187-192.

Carrion-Castillo, A., Franke, B., \& Fisher, S. E. (2013). Molecular genetics of dyslexia: an overview. Dyslexia, 19(4), 214-240.

Carvill, G. L., Regan, B. M., Yendle, S. C., O’Roak, B. J., Lozovaya, N., Bruneau, N., et al. (2013). GRIN2A mutations cause epilepsyaphasia spectrum disorders. Nature Genetics, 45(9), 1073-1076.
Chen, Q., Zhu, T., Jones, G., Zhang, J., \& Sun, Y. (2013). First knockdown gene expression in bat (Hipposideros armiger) brain mediated by lentivirus. Molecular Biotechnology, 54(2), 564-571.

Chokas, A. L., Trivedi, C. M., Lu, M. M., Tucker, P. W., Li, S., Epstein, J. A., et al. (2010). Foxp1/2/4-NuRD interactions regulate gene expression and epithelial injury response in the lung via regulation of interleukin-6. The Journal of Biological Chemistry, 285(17), 13304-13313.

Christopher, M. E., Hulslander, J., Byrne, B., Samuelsson, S., Keenan, J. M., Pennington, B., et al. (2013). Modeling the etiology of individual differences in early reading development: evidence for strong genetic influences. Scientific Studies of Reading, 17(5), 350-368.

Clarke, T., Strug, L. J., Murphy, P. L., Bali, B., Carvalho, J., Foster, S., et al. (2007). High risk of reading disability and speech sound disorder in rolandic epilepsy families: case-control study. Epilepsia, 48(12), 2258-2265.

Clovis, Y. M., Enard, W., Marinaro, F., Huttner, W. B., \& De Pietri Tonelli, D. (2012). Convergent repression of Foxp2 3'UTR by miR-9 and miR-132 in embryonic mouse neocortex: implications for radial migration of neurons. Development, 139(18), 3332-3342.

Coop, G., Bullaughey, K., Luca, F., \& Przeworski, M. (2008). The timing of selection at the human FOXP2 gene. Molecular Biology and Evolution, 25(7), 1257-1259.

Cooper, G. M., \& Shendure, J. (2011). Needles in stacks of needles: finding disease-causal variants in a wealth of genomic data. Nature Reviews Genetics, 12(9), 628-640.

Cope, N., Eicher, J. D., Meng, H., Gibson, C. J., Hager, K., Lacadie, C., et al. (2012). Variants in the DYX2 locus are associated with altered brain activation in reading-related brain regions in subjects with reading disability. NeuroImage, 63(1), 148-156.

Coutinho, P., Pavlou, S., Bhatia, S., Chalmers, K. J., Kleinjan, D. A., \& van Heyningen, V. (2011). Discovery and assessment of conserved Pax6 target genes and enhancers. Genome Research, 21(8), 1349 1359.

Coutinho, M. F., Prata, M. J., \& Alves, S. (2012). Mannose-6-phosphate pathway: a review on its role in lysosomal function and dysfunction. Molecular Genetics and Metabolism, 105(4), 542-550.

Daily, D. K., Ardinger, H. H., \& Holmes, G. E. (2000). Identification and evaluation of mental retardation. American Family Physician, 61(4), 1059-1067.

Darki, F., Peyrard-Janvid, M., Matsson, H., Kere, J., \& Klingberg, T. (2012). Three dyslexia susceptibility genes, DYX1C1, DCDC2, and KIAA0319, affect temporo-parietal white matter structure. Biological Psychiatry, 72(8), 671-676.

Davies, G., Tenesa, A., Payton, A., Yang, J., Harris, S. E., Liewald, D., et al. (2011). Genome-wide association studies establish that human intelligence is highly heritable and polygenic. Molecular Psychiatry, 16(10), 996-1005.

de Kovel, C. G., Hol, F. A., Heister, J. G., Willemen, J. J., Sandkuijl, L. A., Franke, B., et al. (2004). Genomewide scan identifies susceptibility locus for dyslexia on Xq27 in an extended Dutch family. Journal of Medical Genetics, 41(9), 652-657.

Dediu, D. (2011). Are languages really independent from genes? If not, what would a genetic bias affecting language diversity look like? Human Biology, 83(2), 279-296.

Dediu, D., \& Levinson, S. C. (2013). On the antiquity of language: the reinterpretation of neandertal linguistic capacities and its consequences. Frontiers in Psychology, 4, 397.

Dennis, M. Y., Paracchini, S., Scerri, T. S., Prokunina-Olsson, L., Knight, J. C., Wade-Martins, R., et al. (2009). A common variant associated with dyslexia reduces expression of the KIAA0319 gene. PLoS Genetics, 5(3), e1000436.

Dennis, E. L., Jahanshad, N., Rudie, J. D., Brown, J. A., Johnson, K., McMahon, K. L., et al. (2011). Altered structural brain connectivity in healthy carriers of the autism risk gene, CNTNAP2. Brain Connectivity, 1(6), 447-459. 
Deriziotis, P., \& Fisher, S. E. (2013). Neurogenomics of speech and language disorders: the road ahead. Genome Biology, 14(4), 204.

Deriziotis, P., O’Roak, B. J., Graham, S. A., Estruch, S. B., Dimitropoulou, D., Bernier, R., et al. (2014). De novo TBR1 mutations in sporadic autism disrupt protein functions. Nature Communications, 5(4954).

des Portes, V. (2013). X-linked mental deficiency. Handbook of Clinical Neurology, 111, 297-306.

DeVries, S. P., \& Patel, A. D. (2013). Two patients with a GRIN2A mutation and childhood-onset epilepsy. Pediatric Neurology, 49(6), $482-485$.

Dimassi, S., Andrieux, J., Labalme, A., Lesca, G., Cordier, M. P., Boute, O., et al. (2013). Interstitial 12p13.1 deletion involving GRIN2B in three patients with intellectual disability. American Journal of Medical Genetics Part A, 161(10), 2564-2569.

Domingues, C. E., Olivera, C. M., Oliveira, B. V., Juste, F. S., Andrade, C. R., Giacheti, C. M., et al. (2014). A genetic linkage study in Brazil identifies a new locus for persistent developmental stuttering on chromosome 10. Genetics and Molecular Research, 13(1), 2094-2101.

Dorfman, R., Nalpathamkalam, T., Taylor, C., Gonska, T., Keenan, K., Yuan, X. W., et al. (2010). Do common in silico tools predict the clinical consequences of amino-acid substitutions in the CFTR gene? Clinical Genetics, 77(5), 464-473.

Ebstein, R. P., Israel, S., Chew, S. H., Zhong, S., \& Knafo, A. (2010). Genetics of human social behavior. Neuron, 65(6), 831-844.

Eicher, J. D., \& Gruen, J. R. (2013). Imaging-genetics in dyslexia: connecting risk genetic variants to brain neuroimaging and ultimately to reading impairments. Molecular Genetics and Metabolism, $110(3), 201-212$

Eicher, J. D., Powers, N. R., Miller, L. L., Akshoomoff, N., Amaral, D. G., Bloss, C. S., et al. (2013). Genome-wide association study of shared components of reading disability and language impairment. Genes, Brain, and Behavior, 12(8), 792-801.

Enard, W. (2011). FOXP2 and the role of cortico-basal ganglia circuits in speech and language evolution. Current Opinion in Neurobiology, 21(3), 415-424.

Enard, W., Przeworski, M., Fisher, S. E., Lai, C. S., Wiebe, V., Kitano, T., et al. (2002). Molecular evolution of FOXP2, a gene involved in speech and language. Nature, 418(6900), 869-872.

Enard, W., Gehre, S., Hammerschmidt, K., Holter, S. M., Blass, T., Somel, M., et al. (2009). A humanized version of Foxp2 affects cortico-basal ganglia circuits in mice. Cell, 137(5), 961-971.

Evans, N., \& Levinson, S. C. (2009). The myth of language universals: language diversity and its importance for cognitive science. The Behavioral and Brain Sciences, 32(5), 429-448. discussion 448494.

Fan, X., Jin, W. Y., \& Wang, Y. T. (2014). The NMDA receptor complex: a multifunctional machine at the glutamatergic synapse. Frontiers in Cellular Neuroscience, 8, 160

Fedurek, P., \& Slocombe, K. E. (2011). Primate vocal communication: a useful tool for understanding human speech and language evolution? Human Biology, 83(2), 153-173.

Ferland, R. J., Cherry, T. J., Preware, P. O., Morrisey, E. E., \& Walsh, C. A. (2003). Characterization of Foxp2 and Foxp1 mRNA and protein in the developing and mature brain. The Journal of Comparative Neurology, 460(2), 266-279.

Feuk, L., Kalervo, A., Lipsanen-Nyman, M., Skaug, J., Nakabayashi, K., Finucane, B., et al. (2006). Absence of a paternally inherited FOXP2 gene in developmental verbal dyspraxia. American Journal of Human Genetics, 79(5), 965-972.

Field, L. L., Shumansky, K., Ryan, J., Truong, D., Swiergala, E., \& Kaplan, B. J. (2013). Dense-map genome scan for dyslexia supports loci at 4q13,16p12,17q22; suggests novel locus at 7q36. Genes, Brain, and Behavior, 12(1), 56-69.
Fisher, S. E. (2015). Translating the genome in human neuroscience. In G. Marcus, \& J. Freeman (Eds.), The future of the brain: Essays by the world's leading neuroscientists (pp. 149-159). Princeton, NJ: Princeton University Press.

Fisher, S. E., \& DeFries, J. C. (2002). Developmental dyslexia: genetic dissection of a complex cognitive trait. Nature Reviews Neuroscience, 3(10), 767-780.

Fisher, S. E., \& Marcus, G. F. (2006). The eloquent ape: genes, brains and the evolution of language. Nature Reviews Genetics, 7(1), 9-20.

Fisher, S. E., \& Scharff, C. (2009). FOXP2 as a molecular window into speech and language. Trends in Genetics, 25(4), 166-177.

Fisher, S. E., \& Vernes, S. C. (2015). Genetics and the Language Sciences. Annual Review of Linguistics, 1. doi:10.1146/annurevlinguist-030514-125024.

Fisher, S. E., Vargha-Khadem, F., Watkins, K. E., Monaco, A. P., \& Pembrey, M. E. (1998). Localisation of a gene implicated in a severe speech and language disorder. Nature Genetics, 18(2), 168-170.

Fitch, W. T. (2010). The Evolution of Language. Cambridge: Cambridge University Press.

Flanagan, S. E., Patch, A. M., \& Ellard, S. (2010). Using SIFT and PolyPhen to predict loss-of-function and gain-of-function mutations. Genetic Testing and Molecular Biomarkers, 14(4), 533-537.

Francks, C., Paracchini, S., Smith, S. D., Richardson, A. J., Scerri, T. S., Cardon, L. R., et al. (2004). A 77-kilobase region of chromosome 6 p22.2 is associated with dyslexia in families from the United Kingdom and from the United States. American Journal of Human Genetics, 75(6), 1046-1058.

French, C. A., \& Fisher, S. E. (2014). What can mice tell us about Foxp2 function? Current Opinion in Neurobiology, 28C, 72-79.

French, C. A., Groszer, M., Preece, C., Coupe, A. M., Rajewsky, K., \& Fisher, S. E. (2007). Generation of mice with a conditional Foxp2 null allele. Genesis, 45(7), 440-446.

French, C. A., Jin, X., Campbell, T. G., Gerfen, E., Groszer, M., Fisher, S. E., et al. (2012). An aetiological Foxp2 mutation causes aberrant striatal activity and alters plasticity during skill learning. Molecular Psychiatry, 17(11), 1077-1085.

Gabel, L. A., Marin, I., LoTurco, J. J., Che, A., Murphy, C., Manglani, M., et al. (2011). Mutation of the dyslexia-associated gene Dcdc2 impairs LTM and visuo-spatial performance in mice. Genes, Brain, and Behavior, 10(8), 868-875.

Galaburda, A. M., Sherman, G. F., Rosen, G. D., Aboitiz, F., \& Geschwind, N. (1985). Developmental dyslexia: four consecutive patients with cortical anomalies. Annals of Neurology, 18(2), 222233.

Gaugler, T., Klei, L., Sanders, S. J., Bodea, C. A., Goldberg, A. P., Lee, A. B., et al. (2014). Most genetic risk for autism resides with common variation. Nature Genetics, 46(8), 881-885.

Gaya-Vidal, M., \& Alba, M. M. (2014). Uncovering adaptive evolution in the human lineage. BMC Genomics, 15(1), 599.

Gialluisi, A., Dediu, D., Francks, C., \& Fisher, S. E. (2013). Persistence and transmission of recessive deafness and sign language: new insights from village sign languages. European Journal of Human Genetics, 21(9), 894-896.

Gialluisi, A., Newbury, D. F., Wilcutt, E. G., Olson, R. K., DeFries, J. C., Brandler, W. M., et al. (2014). Genome-wide screening for DNA variants associated with reading and language traits. Genes, Brain and Behavior, 137(7), 686-701.

Gibson, J., Adams, C., Lockton, E., \& Green, J. (2013). Social communication disorder outside autism? a diagnostic classification approach to delineating pragmatic language impairment, high functioning autism and specific language impairment. Journal of Child Psychology and Psychiatry, and Allied Disciplines, 54(11), 11861197.

Gilissen, C., Hehir-Kwa, J. Y., Thung, D. T., van de Vorst, M., van Bon, B. W., Willemsen, M. H., et al. (2014). Genome sequencing 
identifies major causes of severe intellectual disability. Nature, 511(7509), 344-347.

Graham, S. A., \& Fisher, S. E. (2013). Decoding the genetics of speech and language. Current Opinion in Neurobiology, 23(1), 43-51.

Griebel, U., \& Oller, D. K. (2012). Vocabulary learning in a Yorkshire terrier: slow mapping of spoken words. PLoS One, 7(2), e30182.

Groszer, M., Keays, D. A., Deacon, R. M., de Bono, J. P., PrasadMulcare, S., Gaub, S., et al. (2008). Impaired synaptic plasticity and motor learning in mice with a point mutation implicated in human speech deficits. Current Biology CB, 18(5), 354-362.

Guidugli, L., Carreira, A., Caputo, S. M., Ehlen, A., Galli, A., Monteiro, A. N., et al. (2014). Functional assays for analysis of variants of uncertain significance in BRCA2. Human Mutation, 35(2), 151164.

Haesler, S., Wada, K., Nshdejan, A., Morrisey, E. E., Lints, T., Jarvis, E. D., et al. (2004). FoxP2 expression in avian vocal learners and nonlearners. The Journal of Neuroscience, 24(13), 3164-3175.

Haesler, S., Rochefort, C., Georgi, B., Licznerski, P., Osten, P., \& Scharff, C. (2007). Incomplete and inaccurate vocal imitation after knockdown of FoxP2 in songbird basal ganglia nucleus Area X. PLoS Biology, 5(12), e321.

Hagoort, P. (2014). Nodes and networks in the neural architecture for language: Broca's region and beyond. Current Opinion in Neurobiology, 28C, 136-141.

Han, T. U., Park, J., Domingues, C. F., Moretti-Ferreira, D., Paris, E., Sainz, E., et al. (2014). A study of the role of the FOXP2 and CNTN AP2 genes in persistent developmental stuttering. Neurobiology of Disease, 69, 23-31.

Hancarova, M., Simandlova, M., Drabova, J., Mannik, K., Kurg, A., \& Sedlacek, Z. (2013). A patient with de novo $0.45 \mathrm{Mb}$ deletion of 2p16.1: the role of BCL11A, PAPOLG, REL, and FLJ16341 in the 2p15-p16.1 microdeletion syndrome. American Journal of Medical Genetics Part A, 161A(4), 865-870.

Hannula-Jouppi, K., Kaminen-Ahola, N., Taipale, M., Eklund, R., Nopola-Hemmi, J., Kaariainen, H., et al. (2005). The axon guidance receptor gene ROBO1 is a candidate gene for developmental dyslexia. PLoS Genetics, 1(4), e50.

Harlaar, N., Meaburn, E. L., Hayiou-Thomas, M. E., Davis, O. S., Docherty, S., Hanscombe, K. B., et al. (2014). Genome-wide association study of receptive language ability of 12-year-olds. Journal of Speech, Language, and Hearing Research, 57(1), 96-105.

Hevner, R. F., Shi, L., Justice, N., Hsueh, Y., Sheng, M., Smiga, S., et al. (2001). Tbr1 regulates differentiation of the preplate and layer 6 . Neuron, 29(2), 353-366.

Hilliard, A. T., Miller, J. E., Fraley, E. R., Horvath, S., \& White, S. A. (2012). Molecular microcircuitry underlies functional specification in a basal ganglia circuit dedicated to vocal learning. Neuron, 73(3), 537-552.

Hobaiter, C., \& Byrne, R. W. (2014). The meanings of chimpanzee gestures. Current Biology, 24(14), 1596-1600.

Hoogman, M., Guadalupe, T., Zwiers, M. P., Klarenbeek, P., Francks, C., $\&$ Fisher, S. E. (2014). Assessing the effects of common variation in the FOXP2 gene on human brain structure. Frontiers in Human Neuroscience, 8, 473.

Horner, V., \& de Waal, F. B. (2009). Controlled studies of chimpanzee cultural transmission. Progress in Brain Research, 178, 3-15.

Huguet, G., Ey, E., \& Bourgeron, T. (2013). The genetic landscapes of autism spectrum disorders. Annual Review of Genomics and Human Genetics, 14, 191-213.

Ioannidis, J. P. (2005). Why most published research findings are false. PLoS Medicine, 2(8), e124.

Janik, V. M. (2014). Cetacean vocal learning and communication. Current Opinion in Neurobiology, 28C, 60-65.

Kang, C., \& Drayna, D. (2011). Genetics of speech and language disorders. Annual Review of Genomics and Human Genetics, 12, 145164
Kang, C., Riazuddin, S., Mundorff, J., Krasnewich, D., Friedman, P., Mullikin, J. C., et al. (2010). Mutations in the lysosomal enzymetargeting pathway and persistent stuttering. The New England Journal of Medicine, 362(8), 677-685.

Khan, Z., Ford, M. J., Cusanovich, D. A., Mitrano, A., Pritchard, J. K., \& Gilad, Y. (2013). Primate transcript and protein expression levels evolve under compensatory selection pressures. Science, 342(6162), $1100-1104$.

Kilpinen, H., \& Dermitzakis, E. T. (2012). Genetic and epigenetic contribution to complex traits. Human Molecular Genetics, 21(R1), R24-28.

Kim, H., \& Kim, J. S. (2014). A guide to genome engineering with programmable nucleases. Nature Reviews Genetics, 15(5), 321-334.

Kim, M. S., Pinto, S. M., Getnet, D., Nirujogi, R. S., Manda, S. S., Chaerkady, R., et al. (2014). A draft map of the human proteome. Nature, 509(7502), 575-581.

Kirby, S., Griffiths, T., \& Smith, K. (2014). Iterated learning and the evolution of language. Current Opinion in Neurobiology, 28C, 108114.

Kirkpatrick, R. M., McGue, M., Iacono, W. G., Miller, M. B., Basu, S., \& Pankratz, N. (2014). Low-frequency copy-number variants and general cognitive ability: No evidence of association. Intelligence, 42, 98-106.

Knornschild, M. (2014). Vocal production learning in bats. Current Opinion in Neurobiology, 28C, 80-85.

Konopka, G., Bomar, J. M., Winden, K., Coppola, G., Jonsson, Z. O., Gao, F., et al. (2009). Human-specific transcriptional regulation of CNS development genes by FOXP2. Nature, 462(7270), 213-217.

Kos, M., van den Brink, D., Snijders, T. M., Rijpkema, M., Franke, B., Fernandez, G., et al. (2012). CNTNAP2 and language processing in healthy individuals as measured with ERPs. PLoS One, 7(10), e46995.

Krumm, N., O’Roak, B. J., Shendure, J., \& Eichler, E. E. (2014). A de novo convergence of autism genetics and molecular neuroscience. Trends in Neurosciences, 37(2), 95-105.

Kuo, T. Y., Hong, C. J., \& Hsueh, Y. P. (2009). Bcl11A/CTIP1 regulates expression of DCC and MAP1b in control of axon branching and dendrite outgrowth. Molecular and Cellular Neurosciences, 42(3), 195-207.

Kuo, T. Y., Chen, C. Y., \& Hsueh, Y. P. (2010a). Bcl11A/CTIP1 mediates the effect of the glutamate receptor on axon branching and dendrite outgrowth. Journal of Neurochemistry, 114(5), 1381-1392.

Kuo, T. Y., Hong, C. J., Chien, H. L., \& Hsueh, Y. P. (2010b). X-linked mental retardation gene CASK interacts with Bcl11A/CTIP1 and regulates axon branching and outgrowth. Journal of Neuroscience Research, 88(11), 2364-2373.

Kurt, S., Groszer, M., Fisher, S. E., \& Ehret, G. (2009). Modified soundevoked brainstem potentials in Foxp2 mutant mice. Brain Research, $1289,30-36$

Kurt, S., Fisher, S. E., \& Ehret, G. (2012). Foxp2 mutations impair auditory-motor association learning. PLoS One, 7(3), e33130.

Laffin, J. J., Raca, G., Jackson, C. A., Strand, E. A., Jakielski, K. J., \& Shriberg, L. D. (2012). Novel candidate genes and regions for childhood apraxia of speech identified by array comparative genomic hybridization. Genetics in Medicine, 14(11), 928-936.

Lai, C. S., Fisher, S. E., Hurst, J. A., Vargha-Khadem, F., \& Monaco, A. P. (2001). A forkhead-domain gene is mutated in a severe speech and language disorder. Nature, 413(6855), 519-523.

Lai, C. S., Gerrelli, D., Monaco, A. P., Fisher, S. E., \& Copp, A. J. (2003). FOXP2 expression during brain development coincides with adult sites of pathology in a severe speech and language disorder. Brain, 126(Pt 11), 2455-2462.

Lamminmaki, S., Massinen, S., Nopola-Hemmi, J., Kere, J., \& Hari, R. (2012). Human ROBO1 regulates interaural interaction in auditory pathways. The Journal of Neuroscience, 32(3), 966-971. 
Law, J., Boyle, J., Harris, F., Harkness, A., \& Nye, C. (2000). Prevalence and natural history of primary speech and language delay: findings from a systematic review of the literature. International Journal of Language \& Communication Disorders, 35(2), 165-188.

Le Fevre, A. K., Taylor, S., Malek, N. H., Horn, D., Carr, C. W., AbdulRahman, O. A., et al. (2013). FOXP1 mutations cause intellectual disability and a recognizable phenotype. American Journal of Medical Genetics Part A, 161A(12), 3166-3175.

Lee, W. S., Kang, C., Drayna, D., \& Kornfeld, S. (2011). Analysis of mannose 6-phosphate uncovering enzyme mutations associated with persistent stuttering. The Journal of Biological Chemistry, 286(46), 39786-39793.

Lemke, J. R., Lal, D., Reinthaler, E. M., Steiner, I., Nothnagel, M., Alber, M., et al. (2013). Mutations in GRIN2A cause idiopathic focal epilepsy with rolandic spikes. Nature Genetics, 45(9), 1067-1072.

Lennon, P. A., Cooper, M. L., Peiffer, D. A., Gunderson, K. L., Patel, A., Peters, S., et al. (2007). Deletion of 7q31.1 supports involvement of FOXP2 in language impairment: clinical report and review. American Journal of Medical Genetics Part A, 143A(8), 791-798.

Leonard, L. B. (2014). Specific language impairment across languages. Child Development Perspectives, 8(1), 1-5.

Lesca, G., Rudolf, G., Bruneau, N., Lozovaya, N., Labalme, A., BoutryKryza, N., et al. (2013). GRIN2A mutations in acquired epileptic aphasia and related childhood focal epilepsies and encephalopathies with speech and language dysfunction. Nature Genetics, 45(9), 1061-1066.

Li, S., Weidenfeld, J., \& Morrisey, E. E. (2004). Transcriptional and DNA binding activity of the Foxp1/2/4 family is modulated by heterotypic and homotypic protein interactions. Molecular and Cellular Biology, 24(2), 809-822.

Liegeois, F., Baldeweg, T., Connelly, A., Gadian, D. G., Mishkin, M., \& Vargha-Khadem, F. (2003). Language fMRI abnormalities associated with FOXP2 gene mutation. Nature Neuroscience, 6(11), 1230 1237.

Liegeois, F., Morgan, A. T., Connelly, A., \& Vargha-Khadem, F. (2011). Endophenotypes of FOXP2: dysfunction within the human articulatory network. European Journal of Paediatric Neurology, 15(4), 283-288.

Liu, X. B., Murray, K. D., \& Jones, E. G. (2004). Switching of NMDA receptor $2 \mathrm{~A}$ and $2 \mathrm{~B}$ subunits at thalamic and cortical synapses during early postnatal development. The Journal of Neuroscience, 24(40), 8885-8895.

Luciano, M., Evans, D. M., Hansell, N. K., Medland, S. E., Montgomery, G. W., Martin, N. G., et al. (2013). A genome-wide association study for reading and language abilities in two population cohorts. Genes, Brain, and Behavior, 12(6), 645-652.

Lyn, H., Russell, J. L., Leavens, D. A., Bard, K. A., Boysen, S. T., Schaeffer, J. A., et al. (2014). Apes communicate about absent and displaced objects: methodology matters. Animal Cognition, 17(1), 85-94.

MacDermot, K. D., Bonora, E., Sykes, N., Coupe, A. M., Lai, C. S., Vernes, S. C., et al. (2005). Identification of FOXP2 truncation as a novel cause of developmental speech and language deficits. American Journal of Human Genetics, 76(6), 1074-1080.

Makrythanasis, P., \& Antonarakis, S. E. (2013). Pathogenic variants in non-protein-coding sequences. Clinical Genetics, 84(5), 422-428.

Maricic, T., Gunther, V., Georgiev, O., Gehre, S., Curlin, M., Schreiweis, C., et al. (2013). A Recent Evolutionary Change Affects a Regulatory Element in the Human FOXP2 Gene. Molecular Biology and Evolution, 30(4), 844-852.

Marignier, S., Lesca, G., Marguin, J., Bussy, G., Sanlaville, D., \& des Portes, V. (2012). Childhood apraxia of speech without intellectual deficit in a patient with cri du chat syndrome. European Journal of Medical Genetics, 55(6-7), 433-436.

Mason, K., Rowley, K., Marshall, C. R., Atkinson, J. R., Herman, R., Woll, B., et al. (2010). Identifying specific language impairment in deaf children acquiring British sign language: implications for theory and practice. The British Journal of Developmental Psychology, 28(Pt 1), 33-49.

Matson, J. L., \& Shoemaker, M. (2009). Intellectual disability and its relationship to autism spectrum disorders. Research in Developmental Disabilities, 30(6), 1107-1114.

Matsuzawa, T. (2013). Evolution of the brain and social behavior in chimpanzees. Current Opinion in Neurobiology, 23(3), 443-449.

Mazoyer, B., Zago, L., Jobard, G., Crivello, F., Joliot, M., Perchey, G., et al. (2014). Gaussian mixture modeling of hemispheric lateralization for language in a large sample of healthy individuals balanced for handedness. PLoS One, 9(6), e101165.

McRae, A. F., Wright, M. J., Hansell, N. K., Montgomery, G. W., \& Martin, N. G. (2013). No association between general cognitive ability and rare copy number variation. Behavior Genetics, 43(3), 202-207.

Meng, H., Smith, S. D., Hager, K., Held, M., Liu, J., Olson, R. K., et al. (2005). DCDC2 is associated with reading disability and modulates neuronal development in the brain. Proceedings of the National Academy of Sciences of the United States of America, 102(47), 17053-17058.

Miller, J. E., Spiteri, E., Condro, M. C., Dosumu-Johnson, R. T., Geschwind, D. H., \& White, S. A. (2008). Birdsong decreases protein levels of FoxP2, a molecule required for human speech. Journal of Neurophysiology, 100(4), 2015-2025.

Mitchell, K. J. (2007). The genetics of brain wiring: from molecule to mind. PLoS Biology, 5(4), e113.

Mitchell, K. J. (2012). What is complex about complex disorders? Genome Biology, 13(1), 237.

Moosa, A. N., Jehi, L., Marashly, A., Cosmo, G., Lachhwani, D., Wyllie, E., et al. (2013). Long-term functional outcomes and their predictors after hemispherectomy in 115 children. Epilepsia, 54(10), 17711779.

Murugan, M., Harward, S., Scharff, C., \& Mooney, R. (2013). Diminished FoxP2 levels affect dopaminergic modulation of corticostriatal signaling important to song variability. Neuron, 80(6), 1464-1476.

Musante, L., \& Ropers, H. H. (2014). Genetics of recessive cognitive disorders. Trends in Genetics, 30(1), 32-39.

Nelson, C. S., Fuller, C. K., Fordyce, P. M., Greninger, A. L., Li, H., \& DeRisi, J. L. (2013). Microfluidic affinity and ChIP-seq analyses converge on a conserved FOXP2-binding motif in chimp and human, which enables the detection of evolutionarily novel targets. Nucleic Acids Research, 41(12), 5991-6004.

Neul, J. L., Kaufmann, W. E., Glaze, D. G., Christodoulou, J., Clarke, A. J., Bahi-Buisson, N., et al. (2010). Rett syndrome: revised diagnostic criteria and nomenclature. Annals of Neurology, 68(6), 944-950.

Newbury, D. F., \& Monaco, A. P. (2010). Genetic advances in the study of speech and language disorders. Neuron, 68(2), 309-320.

Newbury, D. F., Bonora, E., Lamb, J. A., Fisher, S. E., Lai, C. S., Baird, G., et al. (2002). FOXP2 is not a major susceptibility gene for autism or specific language impairment. American Journal of Human Genetics, 70(5), 1318-1327.

Newbury, D. F., Winchester, L., Addis, L., Paracchini, S., Buckingham, L. L., Clark, A., et al. (2009). CMIP and ATP2C2 modulate phonological short-term memory in language impairment. American Journal of Human Genetics, 85(2), 264-272.

Newbury, D. F., Mari, F., Sadighi Akha, E., Macdermot, K. D., Canitano, R., Monaco, A. P., et al. (2012). Dual copy number variants involving 16p11 and 6q22 in a case of childhood apraxia of speech and pervasive developmental disorder. European Journal of Human Genetics, 21(4), 361-365.

Newbury, D. F., Monaco, A. P., \& Paracchini, S. (2014). Reading and language disorders: the importance of both quantity and quality. Genes, 5(2), 285-309. 
Ng, P. C., \& Henikoff, S. (2003). SIFT: Predicting amino acid changes that affect protein function. Nucleic Acids Research, 31(13), 3812 3814.

Nudel, R., Simpson, N. H., Baird, G., O’Hare, A., Conti-Ramsden, G., Bolton, P. F., et al. (2014). Genome-wide association analyses of child genotype effects and parent-of-origin effects in specific language impairment. Genes, Brain, and Behavior, 13(4), 418-429.

O'Roak, B. J., Deriziotis, P., Lee, C., Vives, L., Schwartz, J. J., Girirajan, S., et al. (2011). Exome sequencing in sporadic autism spectrum disorders identifies severe de novo mutations. Nature Genetics, 43(6), 585-589.

O’Roak, B. J., Vives, L., Fu, W., Egertson, J. D., Stanaway, I. B., Phelps, I. G., et al. (2012). Multiplex targeted sequencing identifies recurrently mutated genes in autism spectrum disorders. Science, 338(6114), 1619-1622.

Pal, D. K. (2011). Epilepsy and neurodevelopmental disorders of language. Current Opinion in Neurology, 24(2), 126-131.

Palka, C., Alfonsi, M., Mohn, A., Cerbo, R., Guanciali Franchi, P., Fantasia, D., et al. (2012). Mosaic 7q31 deletion involving FOXP2 gene associated with language impairment. Pediatrics, 129(1), e183-188.

Palumbo, O., D’Agruma, L., Minenna, A. F., Palumbo, P., Stallone, R., Palladino, T., et al. (2013). 3p14.1 de novo microdeletion involving the FOXP1 gene in an adult patient with autism, severe speech delay and deficit of motor coordination. Gene, 516(1), 107-113.

Palumbo, O., Fichera, M., Palumbo, P., Rizzo, R., Mazzolla, E., Cocuzza, D. M., et al. (2014). TBR1 is the candidate gene for intellectual disability in patients with a 2 q24.2 interstitial deletion. American Journal of Medical Genetics Part A, 164A(3), 828-833.

Paracchini, S. (2011). Dissection of genetic associations with languagerelated traits in population-based cohorts. Journal of Neurodevelopmental Disorders, 3(4), 365-373.

Paracchini, S., Thomas, A., Castro, S., Lai, C., Paramasivam, M., Wang, Y., et al. (2006). The chromosome 6 p22 haplotype associated with dyslexia reduces the expression of KIAA0319, a novel gene involved in neuronal migration. Human Molecular Genetics, 15(10), 1659-1666

Paracchini, S., Steer, C. D., Buckingham, L. L., Morris, A. P., Ring, S., Scerri, T., et al. (2008). Association of the KIAA0319 dyslexia susceptibility gene with reading skills in the general population. The American Journal of Psychiatry, 165(12), 1576-1584.

Paracchini, S., Ang, Q. W., Stanley, F. J., Monaco, A. P., Pennell, C. E., \& Whitehouse, A. J. (2011). Analysis of dyslexia candidate genes in the Raine cohort representing the general Australian population. Genes, Brain, and Behavior, 10(2), 158-165.

Penagarikano, O., Abrahams, B. S., Herman, E. I., Winden, K. D., Gdalyahu, A., Dong, H., et al. (2011). Absence of CNTNAP2 leads to epilepsy, neuronal migration abnormalities, and core autismrelated deficits. Cell, 147(1), 235-246.

Pennington, B. F., \& Bishop, D. V. (2009). Relations among speech, language, and reading disorders. Annual Review of Psychology, 60, 283-306.

Peschansky, V. J., Burbridge, T. J., Volz, A. J., Fiondella, C., WissnerGross, Z., Galaburda, A. M., et al. (2010). The effect of variation in expression of the candidate dyslexia susceptibility gene homolog Kiaa0319 on neuronal migration and dendritic morphology in the rat. Cerebral Cortex, 20(4), 884-897.

Peter, B., Matsushita, M., \& Raskind, W. H. (2012). Motor sequencing deficit as an endophenotype of speech sound disorder: a genomewide linkage analysis in a multigenerational family. Psychiatric Genetics, 22(5), 226-234.

Peter, B., Button, L., Stoel-Gammon, C., Chapman, K., \& Raskind, W. H. (2013). Deficits in sequential processing manifest in motor and linguistic tasks in a multigenerational family with childhood apraxia of speech. Clinical Linguistics \& Phonetics, 27(3), 163-191.
Peter, B., Matsushita, M., Oda, K., \& Raskind, W. (2014). De novo microdeletion of BCL11A is associated with severe speech sound disorder. American Journal of Medical Genetics Part A, 164(8), 2091-2096.

Petrill, S. A., Deater-Deckard, K., Thompson, L. A., Dethorne, L. S., \& Schatschneider, C. (2006). Reading skills in early readers: genetic and shared environmental influences. Journal of Learning Disabilities, 39(1), 48-55

Pinel, P., Fauchereau, F., Moreno, A., Barbot, A., Lathrop, M., Zelenika, D., et al. (2012). Genetic variants of FOXP2 and KIAA0319/ TTRAP/THEM2 locus are associated with altered brain activation in distinct language-related regions. The Journal of Neuroscience, 32(3), 817-825.

Pinto, D., Delaby, E., Merico, D., Barbosa, M., Merikangas, A., Klei, L., et al. (2014). Convergence of genes and cellular pathways dysregulated in autism spectrum disorders. American Journal of Human Genetics, 94(5), 677-694.

Piton, A., Redin, C., \& Mandel, J. L. (2013). XLID-causing mutations and associated genes challenged in light of data from large-scale human exome sequencing. American Journal of Human Genetics, 93(2), 368-383.

Plomin, R., Haworth, C. M., \& Davis, O. S. (2009). Common disorders are quantitative traits. Nature Reviews Genetics, 10(12), 872-878.

Plomin, R., Haworth, C. M., Meaburn, E. L., Price, T. S., \& Davis, O. S. (2013). Common DNA markers can account for more than half of the genetic influence on cognitive abilities. Psychological Science, 24(4), 562-568.

Pober, B. R. (2010). Williams-Beuren syndrome. The New England Journal of Medicine, 362(3), 239-252.

Preeprem, T., \& Gibson, G. (2014). SDS, a structural disruption score for assessment of missense variant deleteriousness. Frontiers in Genetics, 5, 82.

Raca, G., Baas, B. S., Kirmani, S., Laffin, J. J., Jackson, C. A., Strand, E. A., et al. (2013). Childhood apraxia of speech (CAS) in two patients with 16p11.2 microdeletion syndrome. European Journal of Human Genetics, 21(4), 455-459.

Raza, M. H., Amjad, R., Riazuddin, S., \& Drayna, D. (2012). Studies in a consanguineous family reveal a novel locus for stuttering on chromosome 16q. Human Genetics, 131(2), 311-313.

Raza, M. H., Gertz, E. M., Mundorff, J., Lukong, J., Kuster, J., Schaffer, A. A., et al. (2013). Linkage analysis of a large African family segregating stuttering suggests polygenic inheritance. Human Genetics, 132(4), 385-396.

Reichmuth, C., \& Casey, C. (2014). Vocal learning in seals, sea lions, and walruses. Current Opinion in Neurobiology, 28C, 66-71.

Reimers-Kipping, S., Hevers, W., Paabo, S., \& Enard, W. (2011). Humanized Foxp2 specifically affects cortico-basal ganglia circuits. Neuroscience, 175, 75-84.

Reinthaler, E. M., Lal, D., Jurkowski, W., Feucht, M., Steinbock, H., Gruber-Sedlmayr, U., et al. (2014). Analysis of ELP4, SRPX2, and interacting genes in typical and atypical rolandic epilepsy. Epilepsia, 55(8), e89-93.

Rice, G. M., Raca, G., Jakielski, K. J., Laffin, J. J., Iyama-Kurtycz, C. M., Hartley, S. L., et al. (2012). Phenotype of FOXP2 haploinsufficiency in a mother and son. American Journal of Medical Genetics Part A, $158 A(1), 174-181$.

Richlan, F. (2014). Functional neuroanatomy of developmental dyslexia: the role of orthographic depth. Frontiers in Human Neuroscience, 8 , 347.

Rietveld, C. A., Medland, S. E., Derringer, J., Yang, J., Esko, T., Martin, N. W., et al. (2013). GWAS of 126,559 individuals identifies genetic variants associated with educational attainment. Science, 340(6139), 1467-1471.

Rilling, J. K. (2014). Comparative primate neurobiology and the evolution of brain language systems. Current Opinion in Neurobiology, $28 C, 10-14$. 
Roberts, A. I., Roberts, S. G., \& Vick, S. J. (2014). The repertoire and intentionality of gestural communication in wild chimpanzees. Animal Cognition, 17(2), 317-336.

Rodenas-Cuadrado, P., Ho, J., \& Vernes, S. C. (2014). Shining a light on CNTNAP2: complex functions to complex disorders. European Journal of Human Genetics, 22(2), 171-178.

Roll, P., Rudolf, G., Pereira, S., Royer, B., Scheffer, I. E., Massacrier, A., et al. (2006). SRPX2 mutations in disorders of language cortex and cognition. Human Molecular Genetics, 15(7), 1195-1207.

Roll, P., Vernes, S. C., Bruneau, N., Cillario, J., Ponsole-Lenfant, M., Massacrier, A., et al. (2010). Molecular networks implicated in speech-related disorders: FOXP2 regulates the SRPX2/uPAR complex. Human Molecular Genetics, 19(24), 4848-4860.

Sakai, Y., Shaw, C. A., Dawson, B. C., Dugas, D. V., Al-Mohtaseb, Z., Hill, D. E., et al. (2011). Protein interactome reveals converging molecular pathways among autism disorders. Science Translational Medicine, 3(86), 86ra49.

Salmi, M., Bruneau, N., Cillario, J., Lozovaya, N., Massacrier, A., Buhler, E., et al. (2013). Tubacin prevents neuronal migration defects and epileptic activity caused by rat Srpx2 silencing in utero. Brain, 136(Pt 8), 2457-2473.

Sankaran, V. G., Xu, J., \& Orkin, S. H. (2010). Advances in the understanding of haemoglobin switching. British Journal of Haematology, 149(2), 181-194.

Scerri, T. S., \& Schulte-Korne, G. (2010). Genetics of developmental dyslexia. European Child \& Adolescent Psychiatry, 19(3), 179-197.

Scerri, T. S., Morris, A. P., Buckingham, L. L., Newbury, D. F., Miller, L. L., Monaco, A. P., et al. (2011). DCDC2, KIAA0319 and CMIP are associated with reading-related traits. Biological Psychiatry, 70(3), $237-245$

Scerri, T. S., Darki, F., Newbury, D. F., Whitehouse, A. J., PeyrardJanvid, M., Matsson, H., et al. (2012). The dyslexia candidate locus on $2 \mathrm{p} 12$ is associated with general cognitive ability and white matter structure. PLoS One, 7(11), e50321.

Scharff, C., \& Petri, J. (2011). Evo-devo, deep homology and FoxP2: implications for the evolution of speech and language. Philosophical Transactions of the Royal Society of London. Series B, Biological Sciences, 366(1574), 2124-2140.

Schulz, S. B., Haesler, S., Scharff, C., \& Rochefort, C. (2010). Knockdown of FoxP2 alters spine density in Area X of the zebra finch. Genes, Brain, and Behavior, 9(7), 732-740.

Scott-Van Zeeland, A. A., Abrahams, B. S., Alvarez-Retuerto, A. I., Sonnenblick, L. I., Rudie, J. D., Ghahremani, D., et al. (2010). Altered functional connectivity in frontal lobe circuits is associated with variation in the autism risk gene CNTNAP2. Science Translational Medicine, 2(56), 56ra80.

Sebat, J., Lakshmi, B., Malhotra, D., Troge, J., Lese-Martin, C., \& Walsh, T. (2007). Strong association of de novo copy number mutations with autism. Science, 316(5823), 445-449.

Seyfarth, R. M., \& Cheney, D. L. (2014). The evolution of language from social cognition. Current Opinion in Neurobiology, 28C, 5-9.

Shi, Z., Luo, G., Fu, L., Fang, Z., Wang, X., \& Li, X. (2013). miR-9 and miR-140-5p target FoxP2 and are regulated as a function of the social context of singing behavior in zebra finches. The Journal of Neuroscience, 33(42), 16510-16521.

Shriberg, L. D., Tomblin, J. B. \& McSweeny, J. L. (1999). Prevalence of speech delay in 6-year-old children and comorbidity with language impairment. Journal of Speech, Language, and Hearing Research, 42(6), 1461-81.

Shriberg, L. D., Ballard, K. J., Tomblin, J. B., Duffy, J. R., Odell, K. H., \& Williams, C. A. (2006). Speech, prosody, and voice characteristics of a mother and daughter with a 7;13 translocation affecting FOXP2. Journal of Speech, Language, and Hearing Research, 49(3), 500 525 .

Shriberg, L. D., Jakielski, K. J., \& El-Shanti, H. (2008). Breakpoint localization using array-CGH in three siblings with an unbalanced 4q;16q translocation and childhood apraxia of speech (CAS). American Journal of Medical Genetics, 146A(17), 2227-2233.

Shriberg, L. D., Potter, N. L., \& Strand, E. A. (2011). Prevalence and phenotype of childhood apraxia of speech in youth with galactosemia. Journal of Speech, Language, and Hearing Research, 54(2), 487-519.

Shu, W., Lu, M. M., Zhang, Y., Tucker, P. W., Zhou, D., \& Morrisey, E. E. (2007). Foxp2 and Foxp1 cooperatively regulate lung and esophagus development. Development, 134(10), 1991-2000.

Sia, G. M., Clem, R. L., \& Huganir, R. L. (2013). The human languageassociated gene SRPX2 regulates synapse formation and vocalization in mice. Science, 342(6161), 987-991.

Simonyan, K. (2014). The laryngeal motor cortex: its organization and connectivity. Current Opinion in Neurobiology, 28C, 15-21.

Smith, N. V., \& Tsimpli, I. M. (1995). The mind of a savant: Language learning and modularity. Oxford: Blackwell.

Spiteri, E., Konopka, G., Coppola, G., Bomar, J., Oldham, M., Ou, J., et al. (2007). Identification of the transcriptional targets of FOXP2, a gene linked to speech and language, in developing human brain. American Journal of Human Genetics, 81(6), 1144-1157.

Srivastava, A. K., \& Schwartz, C. E. (2014). Intellectual disability and autism spectrum disorders: Causal genes and molecular mechanisms. Neuroscience and Biobehavioral Reviews, 46(2), 161-174.

St Pourcain, B., Whitehouse, A. J., Ang, W. Q., Warrington, N. M., Glessner, J. T., Wang, K., et al. (2013). Common variation contributes to the genetic architecture of social communication traits. Molecular Autism, 4(1), 34.

St Pourcain, B., Cents, R. A., Whitehouse, A. J., Haworth, C. M., Davis, O. S., \& O'Reilly, P. F. (2014a). Common variation near ROBO2 is associated with expressive vocabulary in infancy. Nature Communications, 16(5), 4831.

St Pourcain, B., Skuse, D. H., Mandy, W. P., Wang, K., Hakonarson, H., Timpson, N. J., et al. (2014b). Variability in the common genetic architecture of social-communication spectrum phenotypes during childhood and adolescence. Molecular Autism, 5(1), 18.

Stessman, H. A., Bernier, R., \& Eichler, E. E. (2014). A genotype-first approach to defining the subtypes of a complex disease. Cell, $156(5), 872-877$.

Stoeger, A. S., \& Manger, P. (2014). Vocal learning in elephants: neural bases and adaptive context. Current Opinion in Neurobiology, 28C, 101-107.

Strauss, K. A., Puffenberger, E. G., Huentelman, M. J., Gottlieb, S., Dobrin, S. E., Parod, J. M., et al. (2006). Recessive symptomatic focal epilepsy and mutant contactin-associated protein-like 2. The New England Journal of Medicine, 354(13), 1370-1377.

Stromswold, K. (2001). The heritability of language: a review and metaanalysis of twin, adoption and linkage studies. Language, 77, 647723.

Szalkowski, C. E., Fiondella, C. G., Galaburda, A. M., Rosen, G. D., Loturco, J. J., \& Fitch, R. H. (2012). Neocortical disruption and behavioral impairments in rats following in utero RNAi of candidate dyslexia risk gene Kiaa0319. International Journal of Developmental Neuroscience, 30(4), 293-302.

Taipale, M., Kaminen, N., Nopola-Hemmi, J., Haltia, T., Myllyluoma, B., Lyytinen, H., et al. (2003). A candidate gene for developmental dyslexia encodes a nuclear tetratricopeptide repeat domain protein dynamically regulated in brain. Proceedings of the National Academy of Sciences of the United States of America, 100(20), 11553-11558.

Takahashi, D. Y., Narayanan, D. Z., \& Ghazanfar, A. A. (2013). Coupled oscillator dynamics of vocal turn-taking in monkeys. Current Biology, 23(21), 2162-2168.

Tan, G. C., Doke, T. F., Ashburner, J., Wood, N. W., \& Frackowiak, R. S. (2010). Normal variation in fronto-occipital circuitry and cerebellar structure with an autism-associated polymorphism of CNTNAP2. NeuroImage, 53(3), 1030-1042. 
Tanner, D., \& Van Hell, J. G. (2014). ERPs reveal individual differences in morphosyntactic processing. Neuropsychologia, 56, 289-301.

Tarkar, A., Loges, N. T., Slagle, C. E., Francis, R., Dougherty, G. W., Tamayo, J. V., et al. (2013). DYX1C1 is required for axonemal dynein assembly and ciliary motility. Nature Genetics, 45(9), 9951003.

Teramitsu, I., \& White, S. A. (2006). FoxP2 regulation during undirected singing in adult songbirds. The Journal of Neuroscience, 26(28), 7390-7394.

Teramitsu, I., Kudo, L. C., London, S. E., Geschwind, D. H., \& White, S. A. (2004). Parallel FoxP1 and FoxP2 expression in songbird and human brain predicts functional interaction. The Journal of Neuroscience, 24(13), 3152-3163.

Teramitsu, I., Poopatanapong, A., Torrisi, S., \& White, S. A. (2010). Striatal FoxP2 is actively regulated during songbird sensorimotor learning. PLoS One, 5(1), e8548.

Thevenon, J., Callier, P., Andrieux, J., Delobel, B., David, A., Sukno, S., et al. (2013). 12p13.33 microdeletion including ELKS/ERC1, a new locus associated with childhood apraxia of speech. European Journal of Human Genetics, 21(1), 82-88.

Thiebaut de Schotten, M., Ffytche, D. H., Bizzi, A., Dell'Acqua, F., Allin, M., Walshe, M., et al. (2011). Atlasing location, asymmetry and inter-subject variability of white matter tracts in the human brain with MR diffusion tractography. NeuroImage, 54(1), 49-59.

Thomas, M. S., Annaz, D., Ansari, D., Scerif, G., Jarrold, C., \& Karmiloff-Smith, A. (2009). Using developmental trajectories to understand developmental disorders. Journal of Speech, Language, and Hearing Research, 52(2), 336-358.

Thompson, P. M., Stein, J. L., Medland, S. E., Hibar, D. P., Vasquez, A. A., Renteria, M. E., et al. (2014). The ENIGMA consortium: largescale collaborative analyses of neuroimaging and genetic data. Brain Imaging and Behavior, 8(2), 153-182.

Threlkeld, S. W., McClure, M. M., Bai, J., Wang, Y., LoTurco, J. J., Rosen, G. D., et al. (2007). Developmental disruptions and behavioral impairments in rats following in utero RNAi of Dyx 1c1. Brain Research Bulletin, 71(5), 508-514.

Tomblin, J. B., Records, N. L., Buckwalter, P., Zhang, X., Smith, E., \& O'Brien, M. (1997). Prevalence of specific language impairment in kindergarten children. Journal of Speech, Language, and Hearing Research, 40(6), 1245-60

Toma, C., Hervas, A., Torrico, B., Balmana, N., Salgado, M., Maristany, M., et al. (2013). Analysis of two language-related genes in autism: a case-control association study of FOXP2 and CNTNAP2. Psychiatric Genetics, 23(2), 82-85.

Tran, C., Wigg, K. G., Zhang, K., Cate-Carter, T. D., Kerr, E., Field, L. L., et al. (2014). Association of the ROBO1 gene with reading disabilities in a family-based analysis. Genes, Brain, and Behavior, 13(4), 430-438.

Traylor, R. N., Dobyns, W. B., Rosenfeld, J. A., Wheeler, P., Spence, J. E., Bandholz, A. M., et al. (2012). Investigation of TBR1 hemizygosity: four individuals with 2q24 microdeletions. Molecular Syndromology, 3(3), 102-112.

Turner, S. J., Hildebrand, M. S., Block, S., Damiano, J., Fahey, M., Reilly, S., et al. (2013). Small intragenic deletion in FOXP2 associated with childhood apraxia of speech and dysarthria. American Journal of Medical Genetics Part A, 161(9), 2321-2326.

Van Bogaert, P. (2013). Epileptic encephalopathy with continuous spikewaves during slow-wave sleep including Landau-Kleffner syndrome. Handbook of Clinical Neurology, 111, 635-640.

van Bokhoven, H. (2011). Genetic and epigenetic networks in intellectual disabilities. Annual Review of Genetics, 45, 81-104.

Vargha-Khadem, F., Watkins, K. E., Price, C. J., Ashburner, J., Alcock, K. J., Connelly, A., et al. (1998). Neural basis of an inherited speech and language disorder. Proceedings of the National Academy of Sciences of the United States of America, 95(21), 12695-12700.

Veltman, J. A., \& Brunner, H. G. (2012). De novo mutations in human genetic disease. Nature Reviews Genetics, 13(8), 565-575.
Venselaar, H., Camilli, F., Gholizadeh, S., Snelleman, M., Brunner, H. G., $\&$ Vriend, G. (2013). Status quo of annotation of human disease variants. BMC Bioinformatics, 14, 352.

Vernes, S. C., Nicod, J., Elahi, F. M., Coventry, J. A., Kenny, N., Coupe, A. M., et al. (2006). Functional genetic analysis of mutations implicated in a human speech and language disorder. Human Molecular Genetics, 15(21), 3154-3167.

Vernes, S. C., Spiteri, E., Nicod, J., Groszer, M., Taylor, J. M., Davies, K. E., et al. (2007). High-throughput analysis of promoter occupancy reveals direct neural targets of FOXP2, a gene mutated in speech and language disorders. American Journal of Human Genetics, 81(6), $1232-1250$.

Vernes, S. C., Newbury, D. F., Abrahams, B. S., Winchester, L., Nicod, J., Groszer, M., et al. (2008). A functional genetic link between distinct developmental language disorders. The New England Journal of Medicine, 359(22), 2337-2345.

Vernes, S. C., Oliver, P. L., Spiteri, E., Lockstone, H. E., Puliyadi, R., Taylor, J. M., et al. (2011). Foxp2 regulates gene networks implicated in neurite outgrowth in the developing brain. PLoS Genetics, 7(7), e1002145.

Villanueva, P., Newbury, D. F., Jara, L., De Barbieri, Z., Mirza, G., Palomino, H. M., et al. (2011). Genome-wide analysis of genetic susceptibility to language impairment in an isolated Chilean population. European Journal of Human Genetics, 19(6), 687-695.

Wang, Y., Yin, X., Rosen, G., Gabel, L., Guadiana, S. M., Sarkisian, M. R., et al. (2011). Dcdc2 knockout mice display exacerbated developmental disruptions following knockdown of doublecortin. Neuroscience, 190, 398-408.

Watkins, K. (2011). Developmental disorders of speech and language: from genes to brain structure and function. Progress in Brain Research, 189, 225-238.

Watkins, K. E., Gadian, D. G., \& Vargha-Khadem, F. (1999). Functional and structural brain abnormalities associated with a genetic disorder of speech and language. American Journal of Human Genetics, 65(5), 1215-1221.

Watkins, K. E., Vargha-Khadem, F., Ashburner, J., Passingham, R. E., Connelly, A., Friston, K. J., et al. (2002). MRI analysis of an inherited speech and language disorder: structural brain abnormalities. Brain, 125(3), 465-478.

Whalley, H. C., O'Connell, G., Sussmann, J. E., Peel, A., Stanfield, A. C., Hayiou-Thomas, M. E., et al. (2011). Genetic variation in CNTN AP2 alters brain function during linguistic processing in healthy individuals. American Journal of Medical Genetics Part B, 156B(8), 941-948.

Whitehouse, A. J., Bishop, D. V., Ang, Q. W., Pennell, C. E., \& Fisher, S. E. (2011a). CNTNAP2 variants affect early language development in the general population. Genes, Brain, and Behavior, 10(4), 451456.

Whitehouse, A. J., Robinson, M., \& Zubrick, S. R. (2011b). Late talking and the risk for psychosocial problems during childhood and adolescence. Pediatrics, 128(2), e324-332.

Willsey, A. J., Sanders, S. J., Li, M., Dong, S., Tebbenkamp, A. T., Muhle, R. A., et al. (2013). Coexpression networks implicate human midfetal deep cortical projection neurons in the pathogenesis of autism. Cell, 155(5), 997-1007.

Wiszniewski, W., Hunter, J. V., Hanchard, N. A., Willer, J. R., Shaw, C., Tian, Q., et al. (2013). TM4SF20 ancestral deletion and susceptibility to a pediatric disorder of early language delay and cerebral white matter hyperintensities. American Journal of Human Genetics, 93(2), 197-210.

Wohlgemuth, S., Adam, I., \& Scharff, C. (2014). FoxP2 in songbirds. Current Opinion in Neurobiology, 28C, 86-93.

Wong, P. C., Perrachione, T. K., Gunasekera, G., \& Chandrasekaran, B. (2009). Communication disorders in speakers of tone languages: etiological bases and clinical considerations. Seminars in Speech and Language, 30(3), 162-173. 
Worthey, E. A., Raca, G., Laffin, J. J., Wilk, B. M., Harris, J. M., Jakielski, K. J., et al. (2013). Whole-exome sequencing supports genetic heterogeneity in childhood apraxia of speech. Journal of Neurodevelopmental Disorders, 5(1), 29.

Zeesman, S., Nowaczyk, M. J., Teshima, I., Roberts, W., Cardy, J. O., Brian, J., et al. (2006). Speech and language impairment and oromotor dyspraxia due to deletion of $7 \mathrm{q} 31$ that involves FOXP2. American Journal of Medical Genetics Part A, 140(5), 509-514.

Zhou, B., Zhong, Q., Minoo, P., Li, C., Ann, D. K., Frenkel, B., et al. (2008). Foxp2 inhibits Nkx2.1-mediated transcription of
SP-C via interactions with the Nkx2.1 homeodomain. American Journal of Respiratory Cell and Molecular Biology, 38(6), 750758.

Zuberbuhler, K. (2014). Experimental field studies with non-human primates. Current Opinion in Neurobiology, 28C, 150-156.

Zweier, C., de Jong, E. K., Zweier, M., Orrico, A., Ousager, L. B., Collins, A. L., et al. (2009). CNTNAP2 and NRXN1 are mutated in autosomal-recessive Pitt-Hopkins-like mental retardation and determine the level of a common synaptic protein in Drosophila. American Journal of Human Genetics, 85(5), 655-666. 